\title{
Epidemiology and Etiology of Leukemia and Lymphoma
}

\author{
Jordan A. Baeker Bispo, ${ }^{1}$ Paulo S. Pinheiro, ${ }^{2}$ and Erin K. Kobetz ${ }^{3}$ \\ ${ }^{1}$ Department of Public Health Sciences, Miller School of Medicine, University of Miami, Miami, \\ Florida 33136, USA \\ ${ }^{2}$ Sylvester Comprehensive Cancer Center and Department of Public Health Sciences, Miller School \\ of Medicine, University of Miami, Miami, Florida 33136, USA \\ ${ }^{3}$ Sylvester Comprehensive Cancer Center and Department of Medicine, Miller School of Medicine, \\ University of Miami, Miami, Florida 33136, USA \\ Correspondence: jab549@miami.edu
}

\begin{abstract}
Available evidence suggests that the incidence of leukemia and lymphoma tends to be higher in highly developed regions of the world and among Whites in the United States. Temporal trends in incidence are dynamic and multifactorial; for instance, the incidence of nonHodgkin's lymphoma increased around the turn of the century, in part because of the acquired immune deficiency syndrome (AIDS) epidemic. Most leukemias and lymphomas are sporadic and the specific etiology remains elusive. Still, research shows that these malignancies often develop in the context of genetic abnormalities, immunosuppression, and exposure to risk factors like ionizing radiation, carcinogenic chemicals, and oncogenic viruses. The prognosis varies by subtype, with poorer survival outcomes for acute leukemias among adults, and more favorable outcomes for Hodgkin's lymphoma. At a time when specific prevention efforts targeting these malignancies are nonexistent, there is a great need to ensure equitable access to diagnostic services and treatments worldwide.
\end{abstract}

$\mathrm{H}^{2}$ ematopoiesis is the highly regulated process by which stem cells differentiate and mature into erythrocytes, megakaryocytes, and immune cells of myeloid, lymphoid, or monocytic lineage in bone marrow or lymphatic tissues. Genetic errors, such as reciprocal chromosomal translocations, chromosomal deletions, point mutations, and epigenetic alterations, can arrest the maturation of stem cells across different stages of hematopoiesis, giving rise to the uncontrolled proliferation of immature, leukemic immune cells. Leukemia refers to the clonal expansion of leukemic cells in the bone marrow, classically resulting in elevated numbers of cells of the affected lineage in circulating blood and, with certain lymphoid malignancies, abnormal cellular proliferation in lymphatic tissue. Lymphomas are neoplasms of well-differentiated B and $\mathrm{T}$ lymphocytes, which typically present as malignant masses in lymphatic tissue. Leukemias are generally classified into subtypes defined by cell lineage (lymphocytic or myeloid) and stage of maturation arrest (acute or chronic). Mature lymphoid neoplasms are classified

Editors: Michael G. Kharas, Ross L. Levine, and Ari M. Melnick

Additional Perspectives on Leukemia and Lymphoma: Molecular and Therapeutic Insights available at

www.perspectivesinmedicine.org

Copyright (C) 2020 Cold Spring Harbor Laboratory Press; all rights reserved; doi: 10.1101/cshperspect.a034819

Cite this article as Cold Spring Harb Perspect Med 2020;10:a034819 
J.A. Baeker Bispo et al.

broadly into three groups: mature B-cell neoplasms, mature T- or natural killer (NK)-cell neoplasms, and Hodgkin's lymphoma (HL). Collectively, B- and T/NK-cell neoplasms comprise non-Hodgkin's lymphomas (NHLs), a heterogeneous group of more than 60 subtypes. HL arises from B cells, but is distinguished from NHL morphologically by the presence of Reed-Sternberg clonal tumor cells, which are large and often multinucleated.

In this review, we discuss the epidemiology and etiology of leukemia (overall and by subtype), NHL, and HL. Our discussion emphasizes racial/ethnic and age-related disparities in disease burden, as illustrated in part by Figure 1 (patterns of disease incidence) and Figure 2 (patterns of 5-yr relative survival). It should be noted that the World Health Organization (WHO) classification for hematopoietic neoplasms is based on cell of origin, and some forms of leukemia and lymphomas are thus considered different presentations of the same disease. Examples include chronic lymphocytic leukemia and small cell lymphoma (a form of mature B-cell lymphoma; CLL/SLL), and acute lymphocytic leukemia and acute precursor B- and T-cell lymphoblastic leukemia/lymphoma (ALL/LBL). Clinically, CLL/SLL is considered a lymphoma. However, population-based cancer surveillance programs typically count CLL/SLL cases as either leukemias or lymphomas depending on whether the cancer cells were found in the bone marrow, blood, or lymph nodes. Here we present CLL/SLL and ALL/LBL as primarily leukemias, recognizing the overlapping classifications.

\section{GLOBAL EPIDEMIOLOGY OF LEUKEMIA}

The World Health Organization's International Agency for Research on Cancer (IARC) produces global estimates for all cancers contained in the GLOBOCAN database, using data from mostly high-quality population-based cancer registries worldwide. The Institute for Health Metrics and Evaluation's Global Burden of Disease (GBD) study also produces estimates through modeling techniques that incorporate data from numerous additional sources, includ- ing lower-quality cancer registries in countries that are disproportionately low and middle income.

According to GLOBOCAN, leukemia was the 15th most commonly diagnosed cancer and 11th leading cause of cancer mortality worldwide in 2018, accounting for 437,033 incident cancer cases and 309,006 cancer deaths. Globally, the leukemia disease burden is higher among males than females. In 2018, the age-standardized incidence rate for males was 6.1 per 100,000 compared to 4.3 per 100,000 for females. Mortality was also higher in males (4.2 per 100,000) than females (2.8 per 100,000) (Bray et al. 2018). The age distribution of chronic leukemia is generally unimodal, with incidence rates that tend to increase with age. ALL and acute myeloid leukemia (AML), which are important diseases in childhood, accordingly have bimodal age distributions. By GBD estimates, the total number of leukemia cases globally increased by $26 \%$ from 2005 to 2015, and population growth and aging accounted for all but 3\% of this (Fitzmaurice et al. 2017).

The geographic distribution of leukemia burden is patterned by country-level development, with age-standardized incidence, and mortality higher in more developed countries. The IARC classifies 185 countries in the GLOBOCAN database according to the human development index (HDI), a composite measure of life expectancy, education, and standard of living. In 2018, incidence in high/very high HDI countries substantially exceeded that of low/medium HDI countries (7.5 vs. 4.0 per 100,000 for males; 5.3 vs. 3.0 per 100,000 for females). The same was true for mortality in high/very high HDI countries and low/medium countries (4.5 vs. 3.2 per 100,000 for males; 2.9 vs. 2.4 per 100,000 for females) (Bray et al. 2018).

\section{EPIDEMIOLOGY OF LEUKEMIA IN THE UNITED STATES}

In the United States, national trends in leukemia incidence and mortality are monitored using data from state population-based cancer registries, namely through the Surveillance, Epidemiology, and End Results program (SEER), 

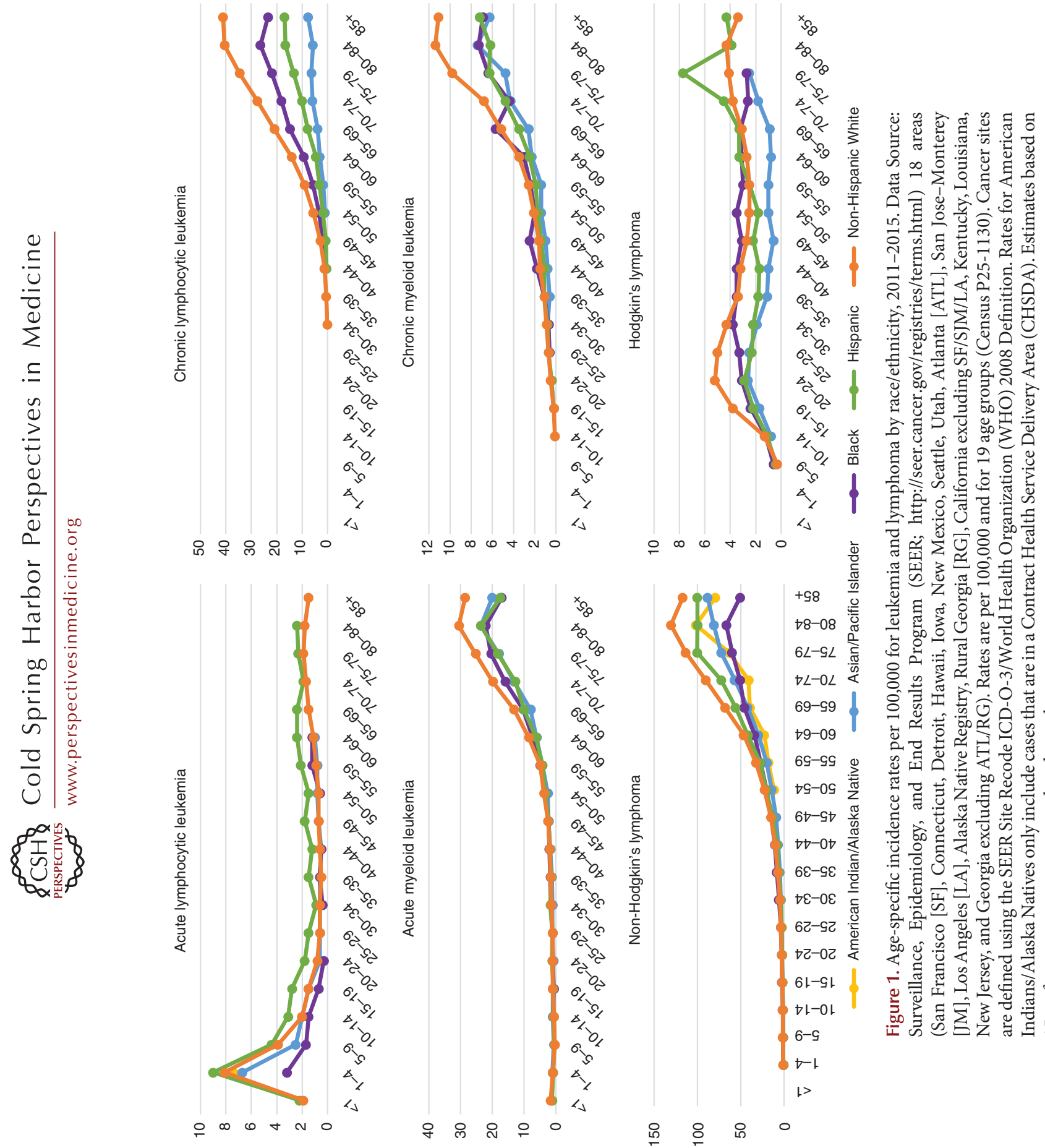

है:

7 نे

(1)

द्य

卷 击

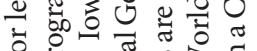

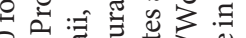

8 造密

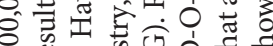

乐

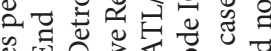

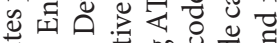

试

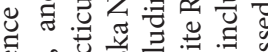

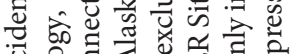

जㅇㅇㅇ है

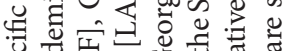

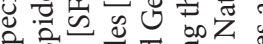

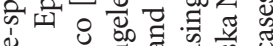

of of.

墕 0

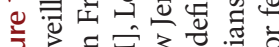

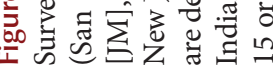

아 잉ㅇㅇ

옹ㅇㅇ 
J.A. Baeker Bispo et al.
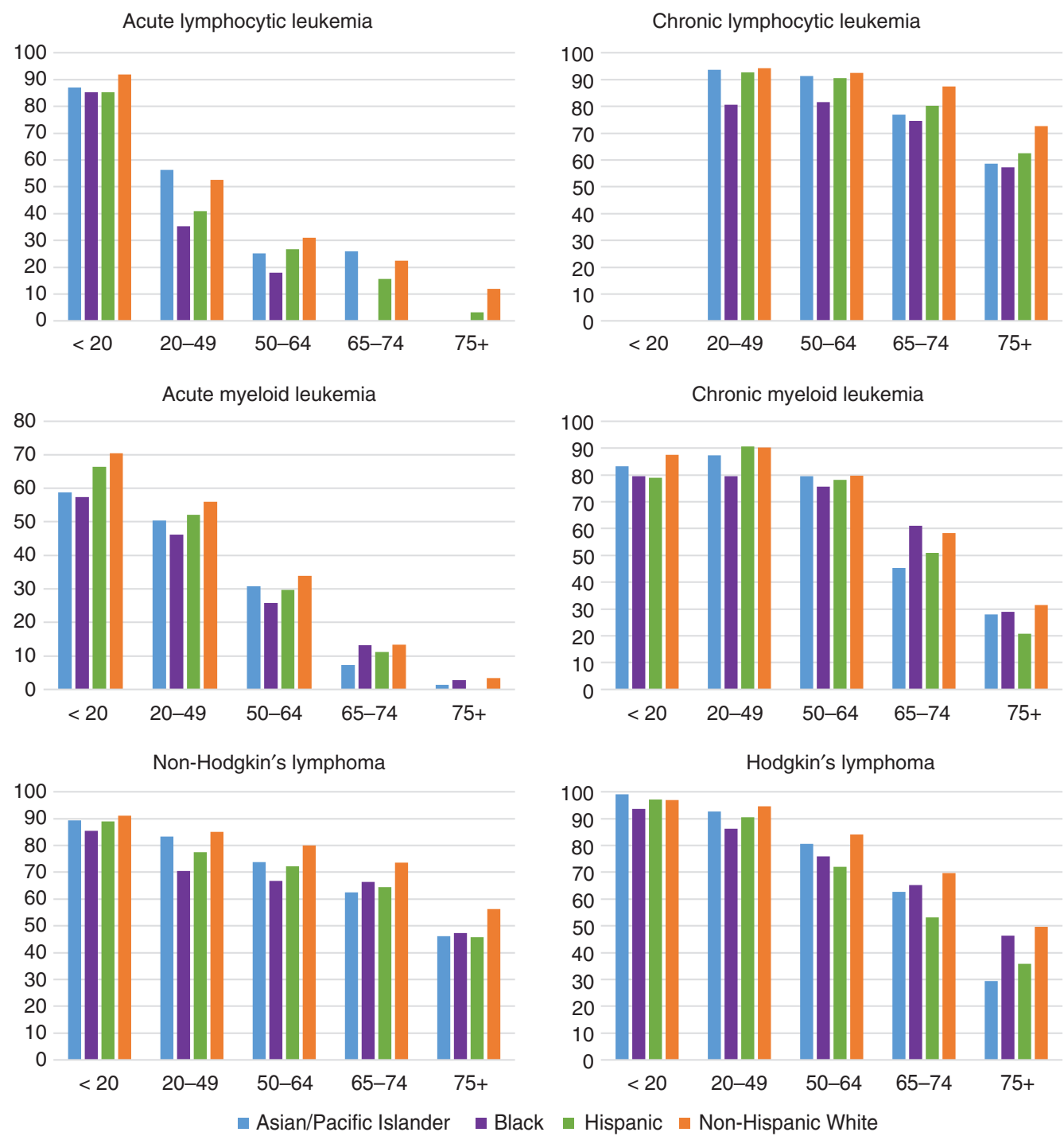

Figure 2. Five-year relative survival proportions for leukemia and lymphoma by race/ethnicity and age, 20082014. Data Source: Surveillance, Epidemiology, and End Results Program (SEER; http://seer.cancer.gov/ registries/terms.html) 18 areas (San Francisco [SF], Connecticut, Detroit, Hawaii, Iowa, New Mexico, Seattle, Utah, Atlanta [ATL], San Jose18 areas Monterey [SJM], Los Angeles [LA], Alaska Native Registry, Rural Georgia [RG], California excluding SF/SJM/LA, Kentucky, Louisiana, New Jersey and Georgia excluding ATL/RG). The 5 -yr survival proportions are calculated using monthly intervals. Cancer sites are defined using the SEER Site Recode ICD-O-3/World Health Organization (WH) 2008 Definition.

and the National Center for Health Statistics. SEER contains high-quality data from 20 regions of the United States, covering $34 \%$ of the population. In 2018, leukemia, including CLL, was the 10th most incident cancer in the United States overall, and the seventh leading cause of cancer death. There were an estimated 60,300 incident cases, accounting for $4 \%$ of cancer diagnoses in males and 3\% in females. Leukemia accounts for $29 \%$ of all childhood cancers. The estimated 24,370 leukemia deaths accounted for $4 \%$ of cancer deaths among both males and fe- 
Epidemiology and Etiology of Leukemia and Lymphoma

males. Since 2006, the incidence of leukemia has increased by an average of $0.6 \%$ per year, whereas mortality has decreased by an annual average of $1.5 \%$ (Siegel et al. 2018).

Overall age-adjusted leukemia incidence in the United States tends to be highest in Whites (15 per 100,000), followed by Blacks (11 per 100,000), and Hispanics (10.6 per 100,000). Incidence among Asian/Pacific Islanders (API; 7.8 per 100,000) and American Indian/Alaskan Natives (AIAN; 8.3 per 100,000) is lower by comparison. Similar racial and ethnic patterns hold for age-adjusted mortality rates, which are also higher for Whites (7 per 100,000), Blacks (5.6 per 100,000$)$, and Hispanics (4.8 per 100,000$)$ than API (3.8 per 100,000) and AIAN (3.3 per 100,000). Although incidence and mortality rates are highest among Whites, survival is poorest for Black patients across age strata. Five-year relative survival for patients of $<65 \mathrm{yr}$ of age at diagnosis is 73\% for Whites and 63\% for Blacks. For ages 65 and older, 5-yr relative survival is $50 \%$ for Whites and $43 \%$ for Blacks (Noone et al. 2017). Importantly, racial/ethnic patterns in leukemia incidence, mortality, and survival vary widely by subtype, as discussed in the sections that follow.

\section{OVERVIEW OF LEUKEMIA RISK FACTORS}

Among those exposures most consistently identified as risk factors for leukemia are radiation (therapeutic, occupational, and wartime-related), chemotherapy, family history, genetic syndromes and abnormalities, chemical exposures (e.g., residential and occupational), and lifestyle factors like smoking. Although some exposures have been associated with specific leukemias, the most notable risk factors have an impact on several subtypes. For example, high doses of ionizing atomic bomb radiation among residents of Japan has been associated with increased mortality from all non-CLL leukemias independently (ALL, AML, and CML) (Preston et al. 1994; Richardson et al. 2009; Hsu et al. 2013). Risk of any non-CLL leukemia has been attributed to ionizing radiation exposure in nuclear workers and radiologists prior to 1950 (Mohan et al. 2003; Yoshinaga et al. 2004; Metz-Flamant et al. 2012) and to therapeutic radiation exposure in patients with primary pelvic cancers (Boice et al. 1987; Wright et al. 2010) or benign disorders like cervical polyps and endometrial hyperplasia (Sakata et al. 2012). Occupational exposure to formaldehyde, a chemical used in many building materials, household products, and industrial disinfectants, has demonstrated particularly strong associations with myeloid leukemias (Beane Freeman et al. 2009; Zhang et al. 2009). The mechanisms by which risk factors shared across leukemias promote oncogenic processes likely exhibit commonalities, although detailed discussion of such mechanisms is beyond the scope of this review.

\section{PEDIATRIC LEUKEMIAS}

Almost all leukemias in the pediatric population are acute types. ALL is the most commonly diagnosed childhood cancer worldwide. It accounts for $\sim 75 \%$ of leukemia cases in children of $<15 \mathrm{yr}$ of age, with a peak incidence rate of 7.8 per 100,000 among children 2-4 yr of age in the United States (Noone et al. 2017). Unlike other leukemias, which are more highly incident among Whites, the incidence of pediatric ALL is higher for Hispanics than for other racial and ethnic groups. For Hispanic children of $<20 \mathrm{yr}$ of age, ALL incidence was 4.3 per 100,000 in the United States from 2001 to 2014, compared to 3.4 for White, 3.0 for AIAN, 3.2 for API, and 1.9 for Black children (Siegel et al. 2017). These rates have largely remained stable since 2008. AML is the second most common hematologic malignancy in children, with peak incidence in the pediatric population occurring in the first year of life.

The causes of leukemia in pediatric patients remain elusive. Several genetic syndromes and immune disorders are associated with both ALL and AML risk, although most cases are not familial. These include Down syndrome (DS), LiFraumeni syndrome, neurofibromatosis, DNA repair deficiency syndromes like Fanconi anemia and Bloom syndrome, and rare inherited bone marrow failure syndromes like Kostmann syndrome, Diamond-Blackfan anemia, dyskeratosis congenita, and Schwachman-Diamond 
J.A. Baeker Bispo et al.

syndrome (Alter 2007; Owen et al. 2008). Approximately $2.1 \%$ of individuals with DS develop leukemia by the age of 5 , and $2.7 \%$ by age 30. Incidence of both ALL and AML among individuals with DS is more than 20 -fold that expected in the general population. The magnitude of DS-associated risk for AML is much higher than that for ALL in children of $<5 \mathrm{yr}$ of age (short interest ratio (SIR) $=154$ vs. SIR $=41$ ), but slightly higher for ALL compared to AML among children and young adults 5-30 yr of age (SIR $=12$ vs. SIR = 10) (Hasle et al. 2000).

Pediatric leukemia is also associated with certain therapeutic exposures, such as chemotherapy with alkylating agents and topoisomerase II inhibitors for primary cancers (Hijiya et al. 2009); diagnostic exposures such as ionizing radiation from CT scans (Pearce et al. 2012); and organ transplantation, which may be related to iatrogenic immunosuppression and exposure to oncogenic viruses (Yanik et al. 2017). Several recent studies indicate that environmental exposure to benzene (e.g., via proximity to automobile traffic and factories), elevates AML risk in children (Honoré et al. 2015; Janitz et al. 2017).

Some studies indicate that early immune stimulation (e.g., via exposure to infection) may be protective against ALL (Rudant et al. 2015; Hwee et al. 2018). Using data pooled across 11 studies from the Childhood Leukemia International Consortium, Rudant et al. (2015) reported a $23 \%$ reduction in risk of ALL among children who attended day care (a proxy for immune stimulation) in the first year of life, with a trend for lower risks at younger start dates. Several important hypotheses articulate an infectious etiology of ALL. Greaves' delayed-infection hypothesis, first outlined in 1988, posits that delayed (e.g., postinfancy) exposure to common infectious agents, for which the immune system is unprepared, elicits an abnormal immune response that triggers ALL (Greaves 1988, 2006). In his model, an initiating genetic event in utero creates a covert preleukemic clone that, upon a second postnatal genetic "hit," progresses to overt leukemia (Greaves 2006). By Kinlen's population-mixing hypothesis, also outlined in 1988 , childhood leukemia is a rare response to a common, unidentified infection that occurs when an infected population "mixes" with a susceptible, nonimmune population (e.g., urban-rural mixing) (Kinlen 1988, 2012). The adrenal hypothesis, more recently proposed by Schmiegelow et al. (2008) postulates that early infection induces the hypothalamus-pituitary-adrenal axis to increase plasma cortisol levels, which may eliminate leukemic and preleukemic cells, and reduces risk of leukemogenesis by suppressing proinflammatory responses. Importantly, not all studies support an infectious etiology of ALL. Designing epidemiologic studies to evaluate these hypotheses is challenging-for example, prospective studies are unfeasible due to the rarity of ALL, and factors like recall bias and temporal ambiguity threaten the validity of retrospective studies (Hwee et al. 2018).

With improvements in recent decades to risk classification and treatments like combination chemotherapies and targeted drug therapies, overall relative survival from ALL is high. Between 1975-1979 and 2003-2009, 5-yr relative survival from pediatric ALL increased dramatically from $57 \%$ to a very favorable $90 \%$ (Ward et al. 2014). AML also saw major gains during this period (from $21 \%$ to $64 \%$ ), although survival remains less favorable than that for ALL. Numerous studies demonstrate that Black and Hispanic children with ALL historically have suffered worse outcomes than their White and non-Hispanic counterparts (Bhatia et al. 2002; Kadan-Lottick et al. 2003; Pui et al. 2012; Tai et al. 2017). Although survival patterns between White and Black children have converged in recent decades (particularly in children of $<15 \mathrm{yr}$ of age), several studies have documented widening disparities for Hispanic children (Wang et al. 2015; Kahn et al. 2016). From 2000 to 2010, ALL mortality among Hispanic children was nearly twice that of Whites $(\mathrm{HR}=1.95)$. Survival disparities may reflect both biologic (e.g., genetic variations associated with ancestry) and socioeconomic (e.g., access to care and treatment adherence) pathways. In one recent study, accounting for the effect of neighborhood socioeconomic status (SES) on hazard of death from ALL reduced the observed racial disparity from $\mathrm{HR}=1.43$ to $\mathrm{HR}=1.22$ for Blacks and from $\mathrm{HR}=1.63$ to $\mathrm{HR}=1.40$ for His- 
panics, respectively, relative to Whites (Kehm et al. 2018). Research on childhood AML has also attributed an elevated risk of death to neighborhood socioeconomic factors-specifically economic and educational disadvantages, housing instability, and immigration-related features (Knoble et al. 2016).

\section{ADULT LEUKEMIAS AND LYMPHOMAS}

\section{Acute Myeloid Leukemia}

Worldwide, AML occurs with greatest frequency in highly developed regions; age-standardized incidence is highest for both males and females in Australia (2.8 and 2.0 per 100,000), Austria (2.7 and 2.2 per 100,000), and the United Kingdom (2.7 and 2.0 per 100,000) (Miranda-Filho et al. 2018). In the United States, an estimated 19,520 cases of AML were diagnosed in 2018. Beginning in young adulthood, the age distribution of AML incidence is exponentially shaped. SEER data show an especially sharp increase in incidence after $75 \mathrm{yr}$ of age, when the rate nearly doubles that of adults aged 60-74 (209 vs. 109 cases per 1,000,000 person-years) (Dores et al. 2012). AML incidence and mortality are higher among Whites than other racial and ethnic groups. For example, age-adjusted incidence among White males in SEER is 5.4 per 100,000, compared to 4.5 for Blacks and 4.1 for Hispanics (Noone et al. 2017). Mortality rates demonstrate a similar racial pattern (3.8, 2.7, and 2.3 per 100,000 for Whites, Blacks, and Hispanics, respectively), and SEER data indicate that these racial and ethnic trends persist across sex and age groups (Zhao et al. 2018).

The causes of genetic mutations that give rise to most cases of AML are largely unknown. Prominent risk factors evaluated in the literature include radiation therapy, chemotherapy, smoking, and other environmental exposures. Morton et al. (2013) have reported that the number of AML diagnoses among patients who received chemotherapy for a first primary cancer is 4.7 times that expected in the general population. Therapy-related myelodysplasia (MDS)/AML is diagnostically classified by treatment typenamely, alkylating agent/radiation regimens or topoisomerase inhibitor-related regimens-and typically occurs within $10 \mathrm{yr}$ of initial therapy (Bhatia 2013). In an early case-control study of AML in breast cancer patients, Curtis et al. reported relative risks of 2.4 for receipt of radiation treatment alone, 10.0 for alkylating agents, and 17.4 for combined radiation-alkylating agent regimens (Curtis et al. 1992). Saso et al. (2000) also found that the risk of MDS/AML in breast cancer patients treated with alkylating agents was 10 -fold that of the general population. Although AML is a relatively rare disease, the absolute excess risk associated with therapy is sizeable (ranging from 5 to 7 excess cases per 100,000 person-years in studies by Howard and colleagues) (Howard et al. 2007, 2008). Another important risk factor for AML in adulthood is smoking. Multiple meta-analysis show elevated risk of AML in smokers. Using data from 23 studies, Fircanis et al. (2014) calculated a $40 \%$ and $25 \%$ increased risk of AML in current and former smokers, respectively, compared to nonsmokers. Pooling data from nine Japanese cohort studies, Ugai et al. also showed an increased risk of near $40 \%$ for current smokers, and a $66 \%$ increase for ever-smokers with a history of more than 30 pack-years compared to nonsmokers (Ugai et al. 2018). Although findings for environmental chemical exposures are less consistent, benzene is a well-established risk factor and has been recognized by the IARC as a cause of AML (International Agency for Research on Cancer 1987; Khalade et al. 2010; Carlos-Wallace et al. 2016; Raaschou-Nielsen et al. 2018). Benzene is one of the most widely used chemicals in the United States, and occupational exposure is highest in industries related to rubber, oil refining, shoe manufacturing, and gasoline.

Several genetic abnormalities are associated with AML risk. Although familial AML is rare, AML is considered part of the natural history of rare inherited bone marrow failure syndromes like Kostmann syndrome, Diamond-Blackfan anemia, dyskeratosis congenita, and Schwachman-Diamond syndrome, as well as DNA repair deficiency syndromes like Fanconi anemia and Bloom syndrome (Alter 2007; Owen et al. 2008). 
J.A. Baeker Bispo et al.

Survival from AML varies substantially by age, with dramatic declines observed for older patients. For those diagnosed before age 65, overall 5-yr relative survival is $45.6 \%$, compared to $7.1 \%$ for those diagnosed at age 65 or older (Noone et al. 2017). Despite some studies demonstrating that White patients present with less favorable prognostic profiles than other racial/ ethnic groups (namely, lower rates of $\mathrm{t}(8 ; 21)$ and acute promyelocytic leukemia), survival outcomes tend to be worst for Black and Hispanic patients (Pulte et al. 2013; Patel et al. 2015b). The survival disparity between Black and White AML patients is especially pronounced for those diagnosed at younger ages (e.g., at $<65 \mathrm{yr}$ of age) (Noone et al. 2017) Even after controlling for age and genetic factors, Black race has been associated with increased risk of death relative to Whites (Patel et al. 2012, 2015b). Some of the racial survival disparity may reflect treatment differences; in California, for example, Black race has been associated with lower odds of receiving chemotherapy and transplant (Patel et al. 2015a). Finally, although AML survival has increased for all racial/ethnic groups since 1991-1996, disparities between groups have also increased as gains have favored Whites, particularly at younger ages. For White patients 15$54 \mathrm{yr}$ of age, survival significantly increased by 12.8 percentage points through 2003-2008, whereas gains for other racial and ethnic groups (4.3 percentage points for AA and Hispanics, 7.1 points for API) did not reach statistical significance (Pulte et al. 2013).

\section{Acute Lymphocytic Leukemia}

Overall, an estimated 5960 total cases of ALL were diagnosed in the United States in 2018 (Siegel et al. 2018). Whereas the incidence of other leukemias generally increases with age, ALL is distinctly bimodal, with pediatric incidence rates far exceeding those for older age groups. Throughout adulthood, incidence is relatively stable around 1 per 100,000, with an increase to 1.9 per 100,000 among elderly adults aged 80-84 (Noone et al. 2017). Like other leukemias, ALL demonstrates a slight male predominance.
Global incidence patterns for ALL are also unique; whereas other leukemias are patterned by HDI and concentrated in Europe, Northern America, and Australia, ALL incidence is highest in South and Central American countriesnamely, Ecuador (2.8 and 3.3 per 100,000 for males and females, respectively), Costa Rica (2.4 and 2.3 per 100,000), and Colombia (2.3 and 2.1 per 100,000) (Miranda-Filho et al. 2018). In the United States, incidence of ALL varies substantially by ethnicity. It is the only leukemia in which incidence, in both pediatric and adult cases, is higher for Hispanics than any other racial or ethnic group.

There are no known causes of ALL. ALL typically arises from noninherited genetic abnormalities. The Philadelphia chromosome, or $\mathrm{t}(9 ; 22)$, is the most common chromosomal translocation in adult ALL (present in $25 \%$ of cases), and unlike in children it is characterized by a highly aggressive clinical course (Gleissner et al. 2002; Pui et al. 2004; Thomas and Heiblig 2016). Many risk factors for adult ALL are similar to those of pediatric ALL, including chemotherapy (e.g., for primary cancers), ionizing radiation (e.g., therapy-related or atomic bomb exposure), and chemical toxins like benzene. The specific mechanisms of risk for these exposures remain unclear.

Survival from ALL declines with age at diagnosis; 5-yr relative survival is $35.8 \%$ for adults 45-54 yr of age, $26.4 \%$ for adults $55-64$ yr or age, and $16.5 \%$ for adults diagnosed at age 65 or older (Noone et al. 2017). When stratified by race and ethnicity, survival is higher for White ALL patients compared to other groups, particularly Black ALL patients. SEER data from 2000 to 2014 indicate that racial survival disparities are more pronounced at younger ages (namely for patients 15-39 yr of age) (Kirtane and Lee 2017). Adult survival disparities have persisted despite Black patients experiencing some of the largest recent improvements in 5-yr survival (e.g., from $24.1 \%$ to $43.4 \%$ among patients 15-44 yr of age between 1997-2002 and 20032008) (Pulte et al. 2013). Hispanic adults, for unclear reasons, also continue to face poorer 5 -yr relative survival than White adults and have experienced smaller gains in survival com- 
Epidemiology and Etiology of Leukemia and Lymphoma

pared to other racial/ethnic groups (Kirtane and Lee 2017).

\section{Chronic Myeloid Leukemia}

CML is cytogenetically characterized by the Philadelphia chromosome--a truncation of chromosome 22 resulting from the reciprocal translocation $\mathrm{t}(9 ; 22)(\mathrm{q} 32 ; \mathrm{q} 11)$. CML accounts for $\sim 15 \%$ of leukemia diagnoses in the United States, or an estimated 8430 new cases in 2018 (Siegel et al. 2018). Incidence increases steadily with age, peaking at 10.3 cases per 100,000 among individuals $80-84 \mathrm{yr}$ of age, although the most frequent age of diagnosis is between 65 and 74 yr of age (comprising 21\% of CML diagnoses). Racial and ethnic patterns in CML incidence are more disparate than for other leukemias. In U.S. males, incidence is highest in Whites (2.4 per 100,000) and AI/AN (2.3 per $100,000)$, whereas for females incidence is highest in Whites and Blacks (1.4 per 100,000) (Noone et al. 2017). Worldwide, there is some variability in CML incidence rates by country, but no clear patterning by HDI. Rates are highest in Australia (1.8 and 1.0 per 100,000 in males and females, respectively), Lithuania (1.6 and 0.9 per 100,000$)$, France (1.7 per 100,000 males), and Uruguay (1.1 per 100,000 females) (Miranda-Filho et al. 2018).

Apart from increasing age, the only known risk factor for CML is exposure to ionizing radiation, which has been described in literature on leukemia among atomic bomb survivors (Heyssel et al. 1960).

CML has a moderate prognosis, with 5-yr relative survival at $68.7 \%$ (Noone et al. 2017). Survival from CML underwent drastic improvements after the introduction of the first tyrosine kinase inhibitor (TKI), imatinib mesylate (Gleevec), in 2001. Prior to this, the prognosis was poor, with overall relative survival $<50 \%$ for patients within $3 \mathrm{yr}$ of diagnosis (Mandal et al. 2013). Although survival has improved across racial and ethnic groups, Mandal et al. found that 3-yr relative survival in the post-imatinib era was nevertheless significantly lower for Black females $(80.5 \%)$ than White females $(90.3 \%)$, and that survival gains favored younger patients
$(<50 \mathrm{yr})$ over older patients. The reason for racial and ethnic disparities in CML survival have been difficult to identify. Wiggins et al. did not find TKI treatment disparities in the United States by race/ethnicity, SES, urban/rural residence, comorbidity, or insurance status after controlling for age (Wiggins et al. 2010). However, age disparities in survival improvement partially reflected less frequent administration of imatinib regimens in elderly patients.

\section{Chronic Lymphocytic Leukemia/Small Cell Lymphoma}

Worldwide, CLL/SLL incidence is highest in countries of very high HDI-namely, Canada and France, where annual rates exceed four new cases per 100,000 males. Incidence is especially low in Asian countries, particularly Japan (0.1 per 100,000$)$, Malaysia (0.1 per 100,000$)$, and the Philippines (0.2 per 100,000). Sex-specific differences are stronger for CLL/SLL than for other leukemias, with incidence among males nearly double that of females, both globally and in the United States (Miranda-Filho et al. 2018).

CLL/SLL is the most common leukemia subtype in the United States, with an estimated 20,940 new cases diagnosed in 2018 (Siegel et al. 2018). Incidence in the United States varies widely by race. The most elevated incidence rates are observed for Whites (5.1 per 100,000) and Blacks (3.6 per 100,000). Incidence is markedly lower, roughly a quarter that of Whites, among the API and AIAN population. Risk of CLL/SLL is strongly age-dependent, with $67 \%$ of diagnoses made to individuals older than age 65 . Among individuals aged 65 and older, incidence is 26.4 per 100,000 ; for the oldest age strata ( 85 and older), incidence is 35.8 per 100,000 (Noone et al. 2017).

Family history of hematologic malignancy is the strongest and most consistent risk factor for CLL/SLL (even if the absolute risk among firstdegree relatives is low), implicating common inherited genetic pathways in CLL/SLL pathogenesis. Large-scale studies using data from the Swedish Cancer Registry have demonstrated that relatives of CLL/SLL cases have a 7.5- to 
J.A. Baeker Bispo et al.

8.5-fold risk of developing CLL/SLL over relatives of controls (Goldin et al. 2004b, 2009). In one of the largest epidemiologic studies on CLL/ SLL risk, which pooled data across 13 case-control studies in Europe, North America, and Australia as part of the International Lymphoma Epidemiology Consortium (InterLymph), history of any hematological malignancy among first-degree relatives was associated with a greater than twofold odds of CLL/SLL odds ratio (OR $=2.17$ ) (Slager et al. 2014).

No single germline mutation has been identified as a causal precursor to CLL/SLL (Goldin and Caporaso 2007). Monoclonal B-cell lymphocytosis (MBL), which is more frequent in high-risk CLL/SLL families than the general population, may be an early genetic factor indicative of inherited predisposition (Rawstron et al. 2002; Goldin et al. 2013). Some studies suggest that geographic and racial variability in CLL/ SLL incidence and prognosis reflect underlying differences in genetic risk factors between groups. For example, Coombs et al. found that the risk allele frequency of most single nucleotide polymorphisms known to confer risk of CLL/SLL in Whites is not associated with risk among Black CLL/SLL patients (Coombs et al. 2012b). The rarity of CLL/SLL among Asians, both in Asia and abroad, also supports the notion of a strong genetic component to disease risk. Several studies have failed to show differences in rates of CLL/SLL between Asian migrants to the United States (foreign-born) and their U.S.-born descendants, suggesting a limited role for the impact of environmental and lifestyle-related exposures on CLL/SLL risk at the population level (Herrinton et al. 1996; Gale et al. 2000; Pan et al. 2002).

Other exposures evaluated as risk factors for CLL/SLL include medical history, biometric characteristics, lifestyle-related factors, and various environmental, occupational, and chemical exposures. Pooled analyses across InterLymph studies have demonstrated elevated odds of CLL/SLL associated with increasing height $(\mathrm{OR}=1.09$ per $10 \mathrm{~cm})$, hepatitis $\mathrm{C}$ seropositivity $(\mathrm{OR}=1.99)$, residential or occupational history on a farm $(\mathrm{OR}=1.20)$, and occupational history as a hairdresser $(\mathrm{OR}=1.77)$ (Slager et al. 2014).
Although studies on chemical exposures are largely inconsistent, the National Institute of Medicine concluded in 2003 that Agent Orange, an dioxin-containing herbicide used in Vietnam, is associated with CLL/SLL in veterans (Institute of Medicine 2009). Protective factors from pooled InterLymph data include history of atopic disorder $(\mathrm{OR}=0.85)$, blood transfusion $(\mathrm{OR}=0.79)$, cigarette smoking $(\mathrm{OR}=0.91)$, and sun exposure $(\mathrm{OR}=0.71$ for highest quartile compared to lowest) (Slager et al. 2014).

Unlike other leukemias, CLL/SLL generally is considered nonradiogenic. Some researchers challenge this conclusion, particularly in light of evidence on CLL/SLL in Czech uranium miners and those exposed to radiation following the Chernobyl nuclear power plant accident (Řeřicha et al. 2006; Hamblin 2008). Results around occupational and medical radiation exposure are inconsistent overall; however, Silver et al. noted that CLL/SLL risk estimates for irradiated patients in medical cohort studies with $>15 \mathrm{yr}$ of follow-up were almost uniformly elevated, albeit nonsignificantly (Silver et al. 2007). The decades-long latency period of CLL/SLL, low case-fatality rate, lack of diagnostic specificity, historical underreporting bias, and difficulty in achieving an adequate sample size are all major challenges in observational studies that examine radiation (and environmental exposures generally) as a risk factor of CLL/SLL (Richardson et al. 2005).

Relative 5-yr survival in the United States overall is high, exceeding $84 \%$ (Noone et al. 2017). Both institutional and population-based studies indicate that Black patients have poorer prognostic profiles at diagnosis, and worse survival, than other racial and ethnic groups (Shenoy et al. 2011; Coombs et al. 2012a; Falchi et al. 2013). Pooled data from MD Anderson and Duke University demonstrated that compared to other races combined, Black patients had worse biological and genetic characteristics at diagnosis, including lower hemoglobin and higher $\beta$-microglobulin; more frequently presented with unmutated IGHV gene, ZAP70 expression, and chromosome $17 \mathrm{p}$ or $11 \mathrm{q}$ deletion; more frequently required first-line therapy; and had shorter overall and event-free survival after 
controlling for prognostic factors (Falchi et al 2013). Using data from SEER, Shoney et al. also showed that Black CLL/SLL patients are diagnosed at younger ages and suffer worse survival than White patients after controlling for prognostic factors like disease stage, extra-nodal primary site, and B symptoms ( $\mathrm{HR}=1.67)$ (Shenoy et al. 2011).

\section{Non-Hodgkin's Lymphomas}

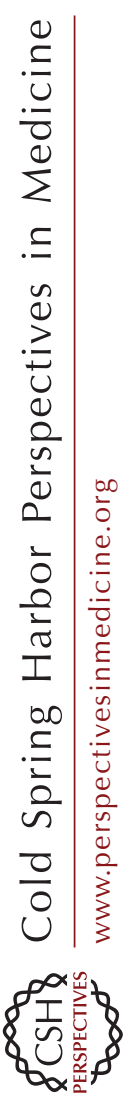

By the latest GLOBOCAN estimates, 509,590 new cases of NHL were projected/estimated worldwide in 2018, and 248,724 NHL deaths (Bray et al. 2018). NHL incidence and mortality rates reflect a male predominance (6.7 vs. 4.7 incidence cases per 100,000 for males and females, respectively; 3.3 vs. 2.0 deaths per 100,000). Across countries characterized by very high $\mathrm{HDI}$, the age-standardized incidence estimate for 2018 (9.3 per 100,000) was more than double that of any other HDI level (high $\mathrm{HDI}=4.6$; medium $\mathrm{HDI}=3.4$; low $\mathrm{HDI}=4.2$ ) . Correspondingly, global regions with the highest incidence include Australia and New Zealand (13.3 per 100,000), North America (12.5 per 100,000), Northern Europe (11.5 per 100,000), and Western Europe (10.1 per 100,000). By contrast, incidence of NHL is lowest across Middle and Central Africa (3.0 and 4.0 per 100,000), Central America (4.0 per 100,000), and Eastern and Southeastern Asia (4.9 per 100,000) (Ferlay et al. 2018).

In the United States, NHL accounted for an estimated 74,680 new cancer diagnoses and 19,910 cancer deaths in 2018, making it the seventh most incident cancer and ninth leading cause of cancer mortality. Nearly $90 \%$ of all lymphomas in the United States are NHL, but this proportion is reduced at younger ages $(62 \%$ in children 0-14 yr, 25\% in adolescents $15-19 \mathrm{yr}$ ) (Ward et al. 2014; Siegel et al. 2018). Diagnosis of NHL is most common in adults 65-74 yr of age (25.6\% of all incidence cases) (Noone et al. 2017).

NHLs historically have been classified as indolent or aggressive according to their usual clinical course, despite substantial patient-topatient variability. Indolent lymphomas include
CLL/SLL, low-grade follicular lymphoma, and marginal zone B-cell lymphoma. Aggressive lymphomas include high-grade follicular lymphoma and diffuse large B-cell lymphoma (DLBCL). Burkitt lymphomas (BL) and precursor B- and T-lymphoblastic leukemia/lymphoma are usually highly aggressive. The most common NHL subtype in the United States is DLBCL (32\%). Excluding CLL/SLL, the second most common subtype is follicular lymphoma (16\%). Less common NHLs include marginal zone lymphoma (9\%), mantel cell lymphoma (4\%), and Burkitt lymphoma/leukemia (2\%) (Teras et al. 2016).

NHL incidence is $>50 \%$ higher in males than females, although there is considerable variability in the sex ratio by NHL subtype; for example, the male predominance is markedly less pronounced for follicular lymphoma and marginal zone lymphoma incidence ratio $(\mathrm{IRR}=1.18$ and 1.05 , respectively), and stronger for mantel cell and Burkitt lymphoma (IRR $=3.07$ and 2.79) (Teras et al. 2016). The strong male predominance of Burkitt lymphoma is likely attributable to its association with human immunodeficiency virus (HIV)/AIDS, which is more prevalent in males than females.

NHL was one of few neoplasms in the United States, and globally, that saw major increases in incidence around the turn of the century. By GBD estimates, the global incidence of NHL rose $23 \%$ from 2005 to 2015 , with the largest increase in middle social-development index countries (Fitzmaurice et al. 2017). From 1975 to 1991 , NHL incidence increased annually by $3.6 \%$ in the United States, and nearly doubled between 1975 and 2008, resulting in what has been described as an NHL epidemic (Levine and Hoover 1992; Weisenburger 1994; Bosetti et al 2008; Shiels et al. 2013). Researchers have hypothesized that the rise in NHL is at least partially attributable to improvements in detection and refinement of the classification system, certain environmental and lifestyle factors, the increasing number of transplant recipients in the population, and the emergence of HIV/AIDS in the early 1980s. NHL (chiefly DLBCL subtypes) is linked etiologically to immunosuppression and considered an AIDS-defining event. Re- 
J.A. Baeker Bispo et al.

cently, NHL incidence has plateaued, with an annual $0.8 \%$ decrease in incidence since 2007 (Noone et al. 2017). Shiels et al. (2013) have suggested that the recent stabilization of NHL rates in the general population is independent of HIV. Among NHL subtypes, decreases in incidence have been most pronounced for CLL/SLL (APC $=-2.7 \%$ and $-2.9 \%$ for males and females, respectively, since 2005), and follicular lymphoma (APC $=-2.2$ for males since 2004, and $-3.6 \%$ for females since 2007). Rates of DLBCL have remained stable since 2001 (Teras et al. 2016).

NHL incidence and mortality tend to be higher in Whites than other racial/ethnic groups, with some variability in racial and ethnic incidence patterns by subtype. Incidence of B-cell NHL is 7\%, $18 \%$, and $72 \%$ higher among Whites compared to Blacks, Hispanics, and API, respectively. On the other hand, the incidence of T/NK-cell NHL is $49 \%$ higher in Blacks than Whites (Teras et al. 2016)

Lymphomas typically are characterized by chromosomal translocations that are not heritable, and research on NHL etiology most consistently supports a role for infection (predominantly viral) and immunosuppression. Specific pathogens that have been linked to risk of NHL include human herpes virus 8 (Oksenhendler et al. 2002; Deloose et al. 2005), hepatitis C (HCV) (Matsuo et al. 2004; Morton et al. 2014), human T-cell lymphotropic virus (Manns et al. 1993; Cleghorn et al. 1995), and Helicobacter pylorus (Parsonnet et al. 1994; Sagaert et al. 2010), among others. In one meta-analysis, the pooled relative risk of NHL associated with HCV infection was 2.5, and the authors estimated that upward of $10 \%$ of NHL in areas with high $\mathrm{HCV}$ prevalence could be attributed to the infection (Dal Maso and Franceschi 2006). In 2009, the IARC Working Group classified EpsteinBarr virus (EBV), a member of the herpes family, a class 1 carcinogen that causes several NHL subtypes, including Burkitt lymphoma, sinonasal angiocentric T-cell lymphoma, and immunosuppression-related NHL (IARC 2012).

The mechanisms of carcinogenesis for viral exposures vary, but EBV has been the focus of most research. Possible oncogenic properties of
EBV include the immortalization of B cells and the encoding of gene products that cause genomic instability, induce cell proliferation, and block apoptosis. Worldwide, EBV infection is ubiquitous; primary infection typically occurs in childhood or adolescence, after which the virus establishes lifelong latency in lymphocytes, with the possibility of reactivation. The carcinogenic potential of EBV frequently arises in the context of sustained immunosuppression or infectious cofactors. For example, there is striking correspondence in the geographic distribution of endemic BL and holoendemic malaria. In tropical zones of subequatorial Africa, endemic BL accounts for $20 \%$ of childhood malignancies, and $\mathrm{EBV}$ is present in nearly $100 \%$ of cases (Orem et al. 2007; Silver et al. 2007). It is generally understood that early coinfection with malaria alters EBV persistence and deteriorates immunoregulatory control of EBV, resulting in a malignant B-cell clone (Rochford et al. 2005; Orem et al. 2007; Chene et al. 2009; Moormann et al. 2011). Several studies support a synergistic effect of malaria and EBV coinfection on risk of childhood BL, with the odds of elevated antibody titers for both EBV and malaria in cases between five to 13 times that of controls (Carpenter et al. 2008; Mutalima et al. 2008).

In individuals with HIV or AIDS, NHL is the second most common malignancy after Kaposi's sarcoma. From 1996 to 2010, incidence of NHL among individuals registered with HIV or AIDS was 193.7 per 100,000 person years, about half of which were DLBCL (Gibson et al. 2014). In one review of population-based studies across the United States, Australia, and Italy, the risk of NHL in individuals with AIDS compared to the general population ranged from 15 -fold for lowgrade NHL to 400-fold for high-grade NHL (Dal Maso and Franceschi 2003). Incidence of NHL in people with AIDS declined dramatically following the introduction of highly active antiretroviral therapy in 1996. In the United States, the relative risk of NHL in people with AIDS compared to the general population reduced from $\mathrm{SIR}=53.2$ to $\mathrm{SIR}=22.6$ between 1990-1995 and 1996-2002 (Engels et al. 2006). In a report by Hernández-Ramírez et al., NHL risks since 1996 have declined significantly for DLBCL and 
Epidemiology and Etiology of Leukemia and Lymphoma

central nervous system NHL, but not BL (Hernández-Ramírez et al. 2017). Nevertheless, incidence of NHL remains elevated for individuals with HIV or AIDS. Analogous to models of malaria as a cofactor in EBV-driven BL pathogenesis, current opinion holds that HIV infection contributes to NHL pathogenesis indirectly through sustained B-cell activation and impaired immunoregulatory control of oncogenic viruses like EBV. Emerging evidence suggests that HIV may also contribute directly through $\mathrm{HIV}$-encoded proteins that enhance B-cell clonogenicity and increase propensity for chromosomal translocations (Dolcetti et al. 2016).

Populations treated with immunosuppressive drugs, including organ transplant recipients and individuals with autoimmune diseases, also experience elevated risk of NHL. In a large cohort study linking 20 years of data from the United States Scientific Registry of Transplants with state and regional cancer registries, Engels et al. reported a more than sevenfold increase in risk of NHL in transplant recipients compared to the general population. Among transplant recipients, an excess of 168.3 cases of NHL per 100,000 person-years could be attributed to transplant (Engels et al. 2011). Relative risks are strongest at younger ages. In a recent registry-linked study on pediatric recipients, $71 \%$ of posttransplant malignancies were NHL; risk of NHL in recipients was 212 times that of the general population, and exceeded 300 for recipients of $<5 \mathrm{yr}$ of age (Yanik et al. 2017). Data from this study also indicate EBV as a cofactor in pathogenesis. Patients who were seronegative for EBV prior to transplantation had 2.7 times the risk of NHL compared to those already seropositive. Presumably, drug-induced immunosuppression impairs the control of newly acquired EBV infection posttransplant, resulting in heightened risk of the oncogenic effects associated with EBV.

Individuals with autoimmune disorders also experience increased risk of NHL. In their metaanalysis of 20 cohort studies, Zintzaras reported that NHL risk was greatest for patients with Sjögren's syndrome $(\mathrm{SIR}=18.8)$, followed by systemic lupus $(\mathrm{SIR}=7.4)$ and rheumatoid arthritis (SIR=3.9) (Zintzaras et al. 2005).
A pooled analysis of 12 InterLymph case-control studies showed more modest effect estimates; Sjögren's syndrome and systemic lupus were associated with 6.5-fold and 2.7-fold odds of NHL, respectively, and both conditions demonstrated significant subtype-specific risk for DLBCL (Ekström Smedby et al. 2008). A large Swedish registry study found that diagnosis with any of 33 autoimmune diseases corresponded to a $60 \%$ increase is risk of NHL (Fallah et al. 2014a). The risk of NHL in this population may reflect the effects of sustained inflammatory activity and disease severity over treatment related immunosuppression or EBV infection (Smedby et al. 2006).

Familial aggregation of NHL has been widely reported in the literature. Several large population-based studies in Europe have reported relative risks of NHL near 1.8 for first-degree relatives of individuals with NHL (Altieri et al. 2005; Goldin et al. 2005). It appears that relatives of NHL patients are at highest risk for subtypeconcordant malignancy; for example, Goldin et al. (2009) found a 10-fold increase in risk of DLBCL in relatives of DLBCL patients, and a fourfold risk of follicular lymphoma in relatives of follicular lymphoma patients. Despite these associations, the absolute risk attributed to familial predisposition is very modest and does not warrant clinical surveillance of first-degree relatives (Cerhan and Slager 2015).

Research on NHL risks linked to environmental exposures and lifestyle-related factors is largely inconclusive. Although studies generally show no or only modest associations between smoking and NHL overall, pooled data from nine InterLymph case-control studies suggest that smoking is positively associated with follicular lymphoma, specifically; the odds of follicular lymphoma were $31 \%$ higher in current smokers than nonsmokers, and $45 \%$ higher in current heavy smokers (with a history of more than 36 pack-years) (Morton et al. 2005). Researchers have hypothesized that exposure to ultraviolet radiation (UV) may confer NHL risk, but results are inconsistent. Thirty years of prospective data from the Nurses' Health study showed that residing in an area with higher versus lower ambient UV radiation was asso- 
J.A. Baeker Bispo et al.

ciated with a $21 \%$ increased risk of NHL (Bertrand et al. 2011). Conversely, several studies have found that UV exposure provides a protective effect. In an analysis with data from the California Teachers Study, exposure to residential UV in the highest versus lowest quartile was associated with a $42 \%$ decrease in risk of NHL overall, with an even stronger protective effect against DLBCL (relative risk $[R R]=0.36$ ) (Chang et al. 2011). Pooled data from InterLymph studies have also shown a protective effect of recreational sun exposure (Morton et al. 2014). InterLymph analyses do not support a link between BMI as a young adult and NHL risk (Morton et al. 2014); however, a recent meta-analysis of 22 studies by Hidayat and colleagues showed a significant $11 \%$ increase in NHL risk per $5 \mathrm{~kg} / \mathrm{m}^{2}$ increase in BMI during early adulthood, and a $21 \%$ increase in risk per $10 \mathrm{~kg}$ increase in weight (Hidayat et al. 2018). Other important risk factors described in pooled analyses of InterLymph studies include occupational history as a farm worker and exposure to hair dye prior to 1980; additional protective factors include history of atopic diseases, blood transfusion, and alcohol consumption of at least one drink per month (Zhang et al. 2008; Morton et al. 2014).

From 2008 to 2014, the overall 5-yr relative survival in patients diagnosed with NHL was $74.1 \%$, but there is considerable variability by subtype, and survival is typically worse for Black NHL patients than those of other racial and ethnic groups (Noone et al. 2017). Five-year survival tends to be higher for follicular lymphoma ( $86 \%$ and $81 \%$ for White and Black males, respectively) and marginal zone lymphomas (89\% and $83 \%$ ), and lower for Burkitt (63\% and $47 \%$ ) and DLBCL (62\% and 55\%) (Teras et al. 2016).

\section{Hodgkin's Lymphoma}

In 2018, HL accounted for an estimated 79,990 incident cancer diagnoses and 26,167 cancer deaths worldwide (Bray et al. 2018). Like NHL, incidence of HL in very high HDI countries (2.1 per 100,000) is more than double that of all other HDI levels. Regions with the most elevated HL incidence rates include Southern, Northern, and
Western Europe (2.8, 2.6, and 2.5 per 100,000), Australia and New Zealand (2.5 per 100,000), and North America (2.4 per 100,000). Incidence is lowest across Eastern and Southern Asia, and sub-Saharan Africa (Ferlay et al. 2018). By GBD estimates, the number of new HL diagnoses globally declined by $6.1 \%$ after accounting for population growth and changing age structure (Fitzmaurice et al. 2017).

HL comprises roughly $10 \%$ of all lymphomas in the United States. In 2018, HL accounted for an estimated 8500 new cancer diagnoses and 1050 cancer deaths (Siegel et al. 2018). Incidence is higher among Whites than other racial and ethnic groups. The age distribution of HL is distinctly bimodal, with peak incidence occurring first among young adults $20-24 \mathrm{yr}$ of age and again among elderly adults 75-79 yr of age (Noone et al. 2017). Most patients diagnosed with $\mathrm{HL}$ are of $<40 \mathrm{yr}$ of age. In the pediatric context, $\mathrm{HL}$ is the most common malignancy in adolescents $15-19 \mathrm{yr}$ of age, accounting for $15 \%$ of cancer diagnoses in this age group (Ward et al. 2014). Of note, one large SEER study using 15 years of data observed distinct racial patterns in the age distribution of HL; for Black males, HL incidence remained relatively stable after peaking in early adulthood, and for Hispanics, incidence rose in an exponential form after age 40, with only a small uptick in incidence during early adulthood (Evens et al. 2012).

Clinical features of HL also vary by race and ethnicity in the United States. Several studies have shown that Blacks and Hispanics are more likely than Whites to be diagnosed with HL of mixed cellularity and less likely to be diagnosed with nodular sclerosis HL (the predominant subtype of classic HL in the United States) (Glaser et al. 2008, 2014; Evens et al. 2012; Grubb et al. 2016). Incidence of nodular sclerosis HL reflects a socioeconomic gradient, whereby higher SES is associated with elevated risk (Clarke et al. 2005). EBV-positive HL, which tends to be of mixed cellularity, is more common in Hispanics than Whites, particularly among foreign-born Hispanics, and those diagnosed at younger and older ages (Glaser et al. 2008, 2014).

Family studies indicate that risk of HL, like NHL, shows a familial predisposition. Large 
population-based studies from Sweden and Denmark have reported relative risks ranging from 3.1-fold to 8.8-fold for first-degree relatives of HL patients (Goldin et al. 2004a; Crump et al. 2012). The high concordance of HL in monozygotic, but not dizygotic, twins indicates that genetic factors play an etiologic role in the development of some cases of HL (Mack et al. 1995).

HL pathogenesis likely involves a complex interplay between genetic susceptibility, immune impairment, and environmental exposures. Abnormal immune response to infectious agents may trigger oncogenic processes that cause HL. By the delayed-exposure model of HL etiology, increased exposure to infection at a young age may protect against HL by promoting early maturation of cellular immunity. Markers of early exposure to common childhood pathogens, like day care attendance (Chang et al. 2004b; Rudant et al. 2011) and having older siblings (Chang et al. 2004a; Altieri et al. 2006), typically show a protective effect against HL. Data linking EBV to HL risk also supports an infectious etiology for some HL. EBV infection in adolescence manifests clinically as infectious mononucleosis (IM). Whereas history of infection with chicken pox, measles, mumps, pertussis, and rubella have shown a protective effect against HL, history of IM is associated with increased HL risk in young adults (Alexander et al. 2000; Hjalgrim et al. 2000). Furthermore, IM-related risk appears specific to EBV-positive HL (Hjalgrim et al. 2003).

Immunosuppression is associated with risk of HL, although typically to a smaller magnitude than that for NHL. In a recent study that evaluated cancer outcomes in 448,258 HIV-infected individuals using linked population-based registries, risk of HL was 4.6-fold and 9.4-fold higher for individuals with HIV only and AIDS, respectively (Hernández-Ramírez et al. 2017). An earlier meta-analysis of cohort studies reported 11-fold and fourfold risks of HL in individuals with HIV/AIDS and transplant recipients, respectively. In AIDS patients, nearly $100 \%$ of classical HL is EBV-positive and of mixed cellularity histology (Bibas and Antinori 2009). Recently, in a large analysis of linked cancer and transplant registry data in the United
States, incidence of HL in pediatric transplants recipients was 19 times that of the general population (Yanik et al. 2017). The risk associated with transplant appears somewhat attenuated $(\mathrm{SIR}=3.6)$ when not restricting to the pediatric population (Engels et al. 2011). Autoimmune diseases characterized by chronic inflammation, like rheumatoid arthritis and systemic lupus, have also been linked to HL, with stronger associations noted for EBV-positive malignancy (Fallah et al. 2014b; Hollander et al. 2015).

Some evidence suggests modest associations between HL and lifestyle factors like smoking and exposure to UV radiation. In a pooled analysis of 12 case-control studies, overall odds of HL in ever smokers were 1.1 times that of never smokers, with higher odds for mixed cellularity $\mathrm{HL}(\mathrm{OR}=1.6)$ and EBV-positive $\mathrm{HL}(\mathrm{OR}=1.8)$. Risks associated with UV exposure also appear specific to EBV-positive HL, but in the opposite direction; in a pooled analysis of four case-control studies, individuals in the highest category of UV exposure had a $44 \%$ reduction in odds of EBV-positive HL compared to those in the lowest category (Monnereau et al. 2013).

Overall, HL has a favorable prognosis; the 5yr relative survival rate exceeded 88\% from 2008 to 2014, and was even higher for individuals younger than $45 \mathrm{yr}$ of age at diagnosis (94\%) and pediatric cases (97\%) (Ward et al. 2014; Noone et al. 2017). Still, SEER and state-specific registry analyses tend to show poorer survival patterns among Black and Hispanic patients compared to White patients (Keegan et al. 2009, 2016; Grubb et al. 2016). In Grubb's analysis of SEER data, overall survival disparities persisted through 25 years of follow-up after controlling for demographics, stage, histology, and treatment; however, the magnitude of differences was less pronounced for Hispanics, and not significant for Blacks, when considering disease-specific survival versus overall survival (Grubb et al. 2016).

\section{CONCLUDING REMARKS}

Leukemias and lymphomas comprise a heterogeneous group of malignancies characterized by the uncontrolled proliferation of cells from pre- 
J.A. Baeker Bispo et al.

dominantly myeloid and lymphoid lineages in hematopoietic and lymphoid tissues. The vast majority of these malignancies are sporadic, and specific etiologic mechanisms remain elusive. Leukemias and lymphomas arise in the context of various host and environmental factors. Host factors include genetic abnormalities (most often chromosomal translocations), rare inherited disorders, and iatrogenic or diseaserelated immunosuppression. Key environmental factors related to leukemia include ionizing radiation, chemotherapy, and carcinogenic chemicals like benzene. Associations between lymphomas and EBV are suggestive of an infectious etiology for certain subtypes such as Burkitt lymphoma and DLBCL.

Leukemia and lymphoma incidence appear to be highest in highly developed regions across Europe, Northern America, and Australia, and among U.S. Whites. An exception to this is ALL, for which incidence is highest in South and Central American countries, and among Hispanics in the United States. Global comparisons in leukemia and lymphoma incidence are made difficult by limited diagnostic infrastructure in less developed countries. Incidence and mortality rates in part reflect a population's access to the formal health-care system, as well as the availability of medical facilities that support morphological, immunohistochemical, and cytogenetic profiling involved in leukemia diagnosis. These factors likely affect overall global counts of leukemia and lymphoma. Furthermore, they may exaggerate differences in overall incidence between more and less developed regions of the world and particularly limit conclusions about observed global patterns that are subtype-specific.

Survival from leukemia and lymphoma varies widely by subtype, ranging from $27.4 \%$ 5-yr relative survival from AML to $84.2 \%$ for CLL/ SLL and $86.6 \%$ for HL. Clearly, new treatments are necessary for poor prognosis malignancies such as ALL and AML among adults both with very low survival. Chemotherapy is the most common treatment modality; additionally, treatment recommendations include radiotherapy, immunotherapy, surgery, and bone marrow or stem cell transplantation depending on the specific disease. Treatment disparities may partially explain poorer survival outcomes among Blacks and Hispanics when compared to their White counterparts. In this regard, equal accessibility to novel treatments, like chimeric antigen receptor $\mathrm{T}$-cell therapy currently being used to treat certain forms of ALL, CLL, and Bcell lymphomas, and precision medicine generally, may be an important focus in the proactive fight against disparities.

Temporal trends in hematologic malignancies are dynamic and sometimes unpredictable, as demonstrated by large global increases in NHL incidence around the turn of the century, because of the HIV epidemic and the increasing number of transplants performed in the developed countries. Understanding and monitoring epidemiologic trends of these malignancies in the context of emerging infections is an important area of research. With the increasing diversity of the United States population, highquality data from population-based cancer registries, and new data from studies on genetic susceptibility, there is great potential for future research to unlock important discoveries on leukemia and lymphoma etiology and distinguish the relative effects of genetic and environmental risk factors.

\section{ACKNOWLEDGMENTS}

The authors thank the Sylvester Comprehensive Cancer Center at the University of Miami, Miller School of Medicine for generously supporting the graduate research assistantship of J.A.B.B.

\section{REFERENCES}

Alexander FE, Jarrett RF, Lawrence D, Armstrong AA, Freeland J, Gokhale DA, Kane E, Taylor GM, Wright DH, Cartwright RA. 2000. Risk factors for Hodgkin's disease by Epstein-Barr virus (EBV) status: Prior infection by EBV and other agents. Br J Cancer 82: 1117-1121. doi:10.1054/bjoc.1999.1049

Alter BP. 2007. Diagnosis, genetics, and management of inherited bone marrow failure syndromes. Hematology Am Soc Hematol Educ Program 2007: 29-39.

Altieri A, Bermejo JL, Hemminki K. 2005. Familial risk for non-Hodgkin lymphoma and other lymphoproliferative malignancies by histopathologic subtype: The Swedish 
Family-Cancer Database. Blood 106: 668-672. doi:10 .1182/blood-2005-01-0140

Altieri A, Castro F, Bermejo JL, Hemminki K. 2006. Number of siblings and the risk of lymphoma, leukemia, and myeloma by histopathology. Cancer Epidemiol Biomarkers Prev 15: 1281-1286. doi:10.1158/1055-9965.EPI-06-0087

Beane Freeman LE, Blair A, Lubin JH, Stewart PA, Hayes RB, Hoover RN, Hauptmann M. 2009. Mortality from lymphohematopoietic malignancies among workers in formaldehyde industries: The National Cancer Institute cohort. J Natl Cancer Inst 101: 751-761. doi:10.1093/jnci/ djp096

Bertrand KA, Chang ET, Abel GA, Zhang SM, Spiegelman D, Qureshi AA, Laden F. 2011. Sunlight exposure, vitamin $\mathrm{D}$, and risk of non-Hodgkin lymphoma in the nurses health study. Cancer Causes Control 22: 1731-1741. doi:10.1007/s10552-011-9849-x

Bhatia S. 2013. Therapy-related myelodysplasia and acute myeloid leukemia. Semin Oncol 40: 666-675. doi:10 $.1053 /$ j.seminoncol.2013.09.013

Bhatia S, Sather HN, Heerema NA, Trigg ME, Gaynon PS, Robison LL. 2002. Racial and ethnic differences in survival of children with acute lymphoblastic leukemia Blood 100: 1957-1964. doi:10.1182/blood-2002-02-0395

Bibas M, Antinori A. 2009. EBV and HIV-related lymphoma. Mediterr J Hematol Infect Dis 1: e2009032.

Boice JD Jr, Blettner M, Kleinerman RA, Stovall M, Moloney WC, Engholm G, Austin DF, Bosch A, Cookfair DL, Krementz ET, et al. 1987. Radiation dose and leukemia risk in patients treated for cancer of the cervix. J Natl Cancer Inst 79: 1295-1311.

Bosetti C, Levi F, Ferlay J, Lucchini F, Negri E, La Vecchia C. 2008. Incidence and mortality from non-Hodgkin lymphoma in Europe: The end of an epidemic? Int J Cancer 123: 1917-1923. doi:10.1002/ijc.23722

Bray F, Ferlay J, Soerjomataram I, Siegel RL, Torre LA, Jemal A. 2018. Global cancer statistics 2018: GLOBOCAN estimates of incidence and mortality worldwide for $36 \mathrm{can}$ cers in 185 countries. CA Cancer J Clin 68: 394-424. doi:10.3322/caac.21492

Carlos-Wallace FM, Zhang L, Smith MT, Rader G, Steinmaus C. 2016. Parental, in utero, and early-life exposure to benzene and the risk of childhood leukemia: A metaanalysis. Am J Epidemiol 183: 1-14. doi:10.1093/aje/ kwv120

Carpenter LM, Newton R, Casabonne D, Ziegler J, Mbulaiteye S, Mbidde E, Wabinga H, Jaffe H, Beral V. 2008 Antibodies against malaria and Epstein-Barr virus in childhood Burkitt lymphoma: A case-control study in Uganda. Int J Cancer 122: 1319-1323. doi:10.1002/ijc .23254

Cerhan JR, Slager SL. 2015. Familial predisposition and genetic risk factors for lymphoma. Blood 126: 2265-2273. doi:10.1182/blood-2015-04-537498

Chang ET, Montgomery SM, Richiardi L, Ehlin A, Ekbom A, Lambe M. 2004a. Number of siblings and risk of Hodgkin's lymphoma. Cancer Epidemiol Biomarkers Prev 13: 1236-1243.

Chang ET, Zheng T, Weir EG, Borowitz M, Mann RB, Spiegelman D, Mueller NE. 2004b. Childhood social environment and Hodgkin's lymphoma: New findings from a population-based case-control study. Cancer Epidemiol Biomarkers Prev 13: 1361-1370.

Chang ET, Canchola AJ, Cockburn M, Lu Y, Wang SS, Bernstein L, Clarke CA, Horn-Ross PL. 2011. Adulthood residential ultraviolet radiation, sun sensitivity, dietary vitamin $\mathrm{D}$, and risk of lymphoid malignancies in the California teachers study. Blood 118: 1591-1599. doi:10 .1182/blood-2011-02-336065

Chene A, Donati D, Orem J, Björkman A, Mbidde ER, Kironde F, Wahlgren M, Bejarano MT. 2009. Endemic Burkitt's lymphoma as a polymicrobial disease: New insights on the interaction between Plasmodium falciparum and Epstein-Barr virus. Semin Cancer Biol 19: 411-420. doi:10.1016/j.semcancer.2009.10.002

Clarke CA, Glaser SL, Keegan THM, Stroup A. 2005. Neighborhood socioeconomic status and Hodgkin's lymphoma incidence in California. Cancer Epidemiol Biomarkers Prev 14: 1441-1447. doi:10.1158/1055-9965.EPI-04-0567

Cleghorn FR, Manns A, Falk R, Hartge P, Hanchard B, Jack N, Williams E, Jaffe E, White F, Bartholomew C, et al. 1995. Effect of human T-lymphotropic virus type I infection on non-Hodgkin's lymphoma incidence. J Natl Cancer Inst 87: 1009-1014. doi:10.1093/jnci/87.13.1009

Coombs CC, Falchi L, Weinberg JB, Ferrajoli A, Lanasa MC 2012a. Chronic lymphocytic leukemia in African Americans. Leuk Lymphoma 53: 2326-2329. doi:10.3109/ 10428194.2012.698276

Coombs CC, Rassenti LZ, Falchi L, Slager SL, Strom SS, Ferrajoli A, Weinberg JB, Kipps TJ, Lanasa MC. 2012b. Single nucleotide polymorphisms and inherited risk of chronic lymphocytic leukemia among African Americans. Blood 120: 1687-1690. doi:10.1182/blood-201202-408799

Crump C, Sundquist K, Sieh W, Winkleby MA, Sundquist J. 2012. Perinatal and family risk factors for Hodgkin's lymphoma in childhood through young adulthood. Am J Epidemiol 176: 1147-1158. doi:10.1093/aje/kws212

Curtis RE, Boice JD Jr, Stovall M, Bernstein L, Greenberg RS, Flannery JT, Schwartz AG, Weyer P, Moloney WC, Hoover RN. 1992. Risk of leukemia after chemotherapy and radiation treatment for breast cancer. $N$ Engl J Med 326: 1745-1751. doi:10.1056/NEJM199206253262605

Dal Maso L, Franceschi S. 2003. Epidemiology of non-Hodgkin lymphomas and other haemolymphopoietic neoplasms in people with AIDS. Lancet Oncol 4: 110-119. doi:10.1016/S1470-2045(03)00983-5

Dal Maso L, Franceschi S. 2006. Hepatitis C virus and risk of lymphoma and other lymphoid neoplasms: A metaanalysis of epidemiologic studies. Cancer Epidemiol Biomarkers Prev 15: 2078-2085. doi:10.1158/1055-9965 .EPI-06-0308

Deloose ST, Smit LA, Pals FT, Kersten MJ, van Noesel CJ, Pals ST. 2005. High incidence of Kaposi sarcoma-associated herpesvirus infection in HIV-related solid immunoblastic/plasmablastic diffuse large B-cell lymphoma. Leukemia 19: 851-855. doi:10.1038/sj.leu.2403709

Dolcetti R, Gloghini A, Caruso A, Carbone A. 2016. A lymphomagenic role for HIV beyond immune suppression? Blood 127: 1403-1409. doi:10.1182/blood-2015-11681411

Dores GM, Devesa SS, Curtis RE, Linet MS, Morton LM. 2012. Acute leukemia incidence and patient survival 
J.A. Baeker Bispo et al.

among children and adults in the United States, 20012007. Blood 119: 34-43. doi:10.1182/blood-2011-04347872

Ekström Smedby K, Vajdic CM, Falster M, Engels EA, Martínez-Maza O, Turner J, Hjalgrim H, Vineis P, Seniori Costantini A, Bracci PM, et al. 2008. Autoimmune disorders and risk of non-Hodgkin lymphoma subtypes: A pooled analysis within the InterLymph Consortium. Blood 111: 4029-4038. doi:10.1182/blood-2007-10119974

Engels EA, Pfeiffer RM, Goedert JJ, Virgo P, McNeel TS, Scoppa SM, Biggar RJ. 2006. Trends in cancer risk among people with AIDS in the United States 1980-2002. AIDS 20: 1645-1654. doi:10.1097/01.aids.0000238411.75324 .59

Engels EA, Pfeiffer RM, Fraumeni JF Jr, Kasiske BL, Israni AK, Snyder JJ, Wolfe RA, Goodrich NP, Bayakly AR, Clarke CA, et al. 2011. Spectrum of cancer risk among US solid organ transplant recipients. J Am Med Assoc 306: 1891-1901. doi:10.1001/jama.2011.1592

Evens AM, Antillón M, Aschebrook-Kilfoy B, Chiu BC. 2012. Racial disparities in Hodgkin's lymphoma: A comprehensive population-based analysis. Ann Oncol 23: 2128-2137. doi:10.1093/annonc/mdr578

Falchi L, Keating MJ, Wang X, Coombs CC, Lanasa MC, Strom S, Wierda WG, Ferrajoli A. 2013. Clinical characteristics, response to therapy, and survival of African American patients diagnosed with chronic lymphocytic leukemia: Joint experience of the MD Anderson Cancer Center and Duke University Medical Center. Cancer 119: 3177-3185. doi:10.1002/cncr.28030

Fallah M, Liu X, Ji J, Försti A, Sundquist K, Hemminki K. 2014a. Autoimmune diseases associated with non-Hodgkin lymphoma: A nationwide cohort study. Ann Oncol 25: 2025-2030. doi:10.1093/annonc/mdu365

Fallah M, Liu X, Ji J, Försti A, Sundquist K, Hemminki K. 2014b. Hodgkin lymphoma after autoimmune diseases by age at diagnosis and histological subtype. Ann Oncol 25: 1397-1404. doi:10.1093/annonc/mdu144

Ferlay J, Ervik M, Lam F, Colombet M, Mery L, Piñeros M, Znaor A, Soerjomataram I, Bray F. 2018. Global cancer observatory: Cancer today. International Agency for Research on Cancer, Lyon, France. Available from https ://gco.iarc.fr/today, accessed January 10, 2019.

Fircanis S, Merriam P, Khan N, Castillo JJ. 2014. The relation between cigarette smoking and risk of acute myeloid leukemia: an updated meta-analysis of epidemiological studies. Am J Hematol 89: E125-E132. doi:10.1002/ajh.23744

Fitzmaurice C, Allen C, Barber RM, Barregard L, Bhutta ZA, Brenner H, Dicker DJ, Chimed-Orchir O, Dandona R, Dandona L, et al. 2017. Global, regional, and national cancer incidence, mortality, years of life lost, years lived with disability, and disability-adjusted life-years for 32 cancer groups, 1990 to 2015: A systematic analysis for the global burden of disease study. JAMA Oncol 3: 524548. doi:10.1001/jamaoncol.2017.1747

Gale RP, Cozen W, Goodman MT, Wang FF, Bernstein L. 2000. Decreased chronic lymphocytic leukemia incidence in Asians in Los Angeles county. Leuk Res 24: 665-669. doi:10.1016/S0145-2126(00)00038-2

Gibson TM, Morton LM, Shiels MS, Clarke CA, Engels EA. 2014. Risk of non-Hodgkin lymphoma subtypes in HIV- infected people during the HAART era: A populationbased study. AIDS 28: 2313-2318. doi:10.1097/QAD .0000000000000428

Glaser SL, Gulley ML, Clarke CA, Keegan TH, Chang ET, Shema SJ, Craig FE, Digiuseppe JA, Dorfman RF, Mann RB, et al. 2008. Racial/ethnic variation in EBV-positive classical Hodgkin lymphoma in California populations. Int J Cancer 123: 1499-1507. doi:10.1002/ijc.23741

Glaser SL, Clarke CA, Chang ET, Yang J, Gomez SL, Keegan TH. 2014. Hodgkin lymphoma incidence in California Hispanics: Influence of nativity and tumor Epstein-Barr virus. Cancer Causes Control 25: 709-725. doi:10.1007/ s10552-014-0374-6

Gleissner B, Gokbuget N, Bartram CR, Janssen B, Rieder H, Janssen JW, Fonatsch C, Heyll A, Voliotis D, Beck J, et al. 2002. Leading prognostic relevance of the BCR-ABL translocation in adult acute B-lineage lymphoblastic leukemia: A prospective study of the German Multicenter Trial Group and confirmed polymerase chain reaction analysis. Blood 99: 1536-1543. doi:10.1182/blood.V99.5 .1536

Goldin LR, Caporaso NE. 2007. Family studies in chronic lymphocytic leukaemia and other lymphoproliferative tumours. Br J Haematol 139: 774-779. doi:10.1111/j.13652141.2007.06810.x

Goldin LR, Pfeiffer RM, Gridley G, Gail MH, Li X, Mellemkjaer L, Olsen JH, Hemminki K, Linet MS. 2004a. Familial aggregation of Hodgkin lymphoma and related tumors. Cancer 100: 1902-1908. doi:10.1002/cncr.20189

Goldin LR, Pfeiffer RM, Li X, Hemminki K. 2004b. Familial risk of lymphoproliferative tumors in families of patients with chronic lymphocytic leukemia: Results from the Swedish family-cancer database. Blood 104: 1850-1854. doi:10.1182/blood-2004-01-0341

Goldin LR, Landgren O, McMaster ML, Gridley G, Hemminki K, Li X, Mellemkjaer L, Olsen JH, Linet MS. 2005. Familial aggregation and heterogeneity of non-Hodgkin lymphoma in population-based samples. Cancer Epidemiol Biomarkers Prev 14: 2402-2406. doi:10.1158/10559965.EPI-05-0346

Goldin LR, Björkholm M, Kristinsson SY, Turesson I, Landgren O. 2009. Elevated risk of chronic lymphocytic leukemia and other indolent non-Hodgkin's lymphomas among relatives of patients with chronic lymphocytic leukemia. Haematologica 94: 647-653. doi:10.3324/haema tol.2008.003632

Goldin LR, McMaster ML, Caporaso NE. 2013. Precursors to lymphoproliferative malignancies. Cancer Epidemiol Biomarkers Prev 22: 533-539. doi:10.1158/1055-9965.EPI$12-1348$

Greaves MF. 1988. Speculations on the cause of childhood acute lymphoblastic leukemia. Leukemia 2: 120-125.

Greaves M. 2006. Infection, immune responses and the aetiology of childhood leukaemia. Nat Rev Cancer 6: 193 203. doi: $10.1038 / \mathrm{nrc} 1816$

Grubb WR, Neboori HJ, Diaz AD, Li H, Kwon D, Panoff J. 2016. Racial and ethnic disparities in the pediatric Hodgkin lymphoma population. Pediatr Blood Cancer 63: 428435. doi: $10.1002 / p b c .25802$

Hamblin TJ. 2008. Have we been wrong about ionizing radiation and chronic lymphocytic leukemia? Leuk Res 32: 523-525. doi:10.1016/j.leukres.2007.08.015 
Hasle H, Clemmensen IH, Mikkelsen M. 2000. Risks of leukaemia and solid tumours in individuals with Down's syndrome. Lancet 355: 165-169. doi:10.1016/S01406736(99)05264-2

Hernández-Ramírez RU, Shiels MS, Dubrow R, Engels EA. 2017. Cancer risk in HIV-infected people in the USA from 1996 to 2012: A population-based, registry-linkage study. Lancet HIV 4: e495-e504. doi:10.1016/S2352-3018 (17)30125-X

Herrinton LJ, Goldoft M, Schwartz SM, Weiss NS. 1996. The incidence of non-Hodgkin's lymphoma and its histologic subtypes in Asian migrants to the United States and their descendants. Cancer Causes Control 7: 224-230. doi:10 .1007/BF00051298

Heyssel R, Brill AB, Woodbury LA, Nishimura ET, Ghose T, Hoshino T, Yamasaki M. 1960. Leukemia in Hiroshima atomic bomb survivors. Blood 15: 313-331.

Hidayat K, Li HJ, Shi BM. 2018. Anthropometric factors and non-Hodgkin's lymphoma risk: Systematic review and meta-analysis of prospective studies. Crit Rev Oncol Hematol 129: 113-123. doi:10.1016/j.critrevonc.2018.05.018

Hijiya N, Ness KK, Ribeiro RC, Hudson MM. 2009. Acute leukemia as a secondary malignancy in children and adolescents: Current findings and issues. Cancer 115: 2335. doi:10.1002/cncr.23988

Hjalgrim H, Askling J, Sorensen P, Madsen M, Rosdahl N, Storm HH, Hamilton-Dutoit S, Eriksen LS, Frisch M, Ekbom A, et al. 2000. Risk of Hodgkin's disease and other cancers after infectious mononucleosis. J Natl Cancer Inst 92: 1522-1528. doi:10.1093/jnci/92.18.1522

Hjalgrim H, Askling J, Rostgaard K, Hamilton-Dutoit S, Frisch M, Zhang JS, Madsen M, Rosdahl N, Konradsen HB, Storm HH, et al. 2003. Characteristics of Hodgkin's lymphoma after infectious mononucleosis. $N$ Engl J Med 349: 1324-1332. doi:10.1056/NEJMoa023141

Hollander P, Rostgaard K, Smedby KE, Chang ET, Amini RM, de Nully Brown P, Glimelius B, Adami HO, Melbye M, Glimelius I, et al. 2015. Autoimmune and atopic disorders and risk of classical Hodgkin's lymphoma. Am J Epidemiol 182: 624-632. doi:10.1093/aje/kwv081

Honoré C, Hémon D, Marquant F, Houot J, Faure L, Roth MH, Goujon S, Clavel J. 2015. Residential proximity to heavy-traffic roads, benzene exposure, and childhood leukemia-The GEOCAP Study, 2002-2007. Am J Epidemiol 182: 685-693. doi:10.1093/aje/kwv111

Howard RA, Gilbert ES, Chen BE, Hall P, Storm H, Pukkala E, Langmark F, Kaijser M, Andersson M, Joensuu H, et al 2007. Leukemia following breast cancer: An international population-based study of 376,825 women. Breast Cancer Res Treat 105: 359-368. doi:10.1007/s10549-006-9460-0

Howard R, Gilbert E, Lynch CF, Hall P, Storm H, Holowaty E, Pukkala E, Langmark F, Kaijser M, Andersson M, et al. 2008. Risk of leukemia among survivors of testicular cancer: A population-based study of 42,722 patients. Ann Epidemiol 18: 416-421. doi:10.1016/j.annepidem.2008 .01 .003

Hsu WL, Preston DL, Soda M, Sugiyama H, Funamoto S, Kodama K, Kimura A, Kamada N, Dohy H, Tomonag $\mathrm{M}$, et al. 2013. The incidence of leukemia, lymphoma and multiple myeloma among atomic bomb survivors: 1950 2001. Radiat Res 179: 361-382. doi:10.1667/RR2892.1
Hwee J, Tait C, Sung L, Kwong JC, Sutradhar R, Pole JD. 2018. A systematic review and meta-analysis of the association between childhood infections and the risk of childhood acute lymphoblastic leukaemia. $\mathrm{Br} J$ Cancer 118: $127-137$. doi:10.1038/bjc. 2017.360

IARC. 2012. IARC monographs on the evaluation of carcinogenic risks to humans, No. 100B. Epstein-Barr Virus, Lyon, France

Institute of Medicine. 2009. Veterans and Agent Orange: Update 2008. National Academies Press (US). National Academy of Sciences, Washington, D.C.

International Agency for Research on Cancer. 1987. Benzene: IARC monographs-100f. International Agency for Research on Cancer, Lyon, France.

Janitz AE, Campbell JE, Magzamen S, Pate A, Stoner JA, Peck JD. 2017. Benzene and childhood acute leukemia in Oklahoma. Environ Res 158: 167-173. doi:10.1016/j .envres.2017.06.015

Kadan-Lottick NS, Ness KK, Bhatia S, Gurney JG. 2003. Survival variability by race and ethnicity in childhood acute lymphoblastic leukemia. J Am Med Assoc 290: 2008-2014. doi:10.1001/jama.290.15.2008

Kahn JM, Keegan THM, Tao L, Abrahão R, Bleyer A, Viny AD. 2016. Racial disparities in the survival of American children, adolescents, and young adults with acute lymphoblastic leukemia, acute myelogenous leukemia, and Hodgkin lymphoma. Cancer 122: 2723-2730. doi:10 $.1002 / \mathrm{cncr} .30089$

Keegan TH, Clarke CA, Chang ET, Shema SJ, Glaser SL. 2009. Disparities in survival after Hodgkin lymphoma: A population-based study. Cancer Causes Control 20: 1881-1892. doi:10.1007/s10552-009-9382-3

Keegan TH, DeRouen MC, Parsons HM, Clarke CA, Goldberg D, Flowers CR, Glaser SL. 2016. Impact of treatment and insurance on socioeconomic disparities in survival after adolescent and young adult Hodgkin lymphoma: A population-based study. Cancer Epidemiol Biomarkers Prev 25: 264-273. doi:10.1158/1055-9965.EPI-15-0756

Kehm RD, Spector LG, Poynter JN, Vock DM, Altekruse SF, Osypuk TL. 2018. Does socioeconomic status account for racial and ethnic disparities in childhood cancer survival? Cancer 124: 4090-4097. doi:10.1002/cncr.31560

Khalade A, Jaakkola MS, Pukkala E, Jaakkola JJ. 2010. Exposure to benzene at work and the risk of leukemia: A systematic review and meta-analysis. Environ Health 9: 31. doi:10.1186/1476-069X-9-31

Kinlen L. 1988. Evidence for an infective cause of childhood leukaemia: Comparison of a Scottish new town with nuclear reprocessing sites in Britain. Lancet 332: 1323-1327. doi:10.1016/S0140-6736(88)90867-7

Kinlen LJ. 2012. An examination, with a meta-analysis, of studies of childhood leukaemia in relation to population mixing. Br J Cancer 107: 1163-1168. doi:10.1038/bjc .2012 .402

Kirtane K, Lee SJ. 2017. Racial and ethnic disparities in hematologic malignancies. Blood 130: 1699-1705. doi:10.1182/blood-2017-04-778225

Knoble NB, Alderfer MA, Hossain MJ. 2016. Socioeconomic status (SES) and childhood acute myeloid leukemia (AML) mortality risk: Analysis of SEER data. Cancer Epidemiol 44: 101-108. doi:10.1016/j.canep.2016.07.007 
J.A. Baeker Bispo et al.

Levine PH, Hoover R. 1992. The emerging epidemic of nonHodgkin's lymphoma: Current knowledge regarding etiological factors. Cancer Epidemiol Biomarkers Prev 1: 515-517.

Mack TM, Cozen W, Shibata DK, Weiss LM, Nathwani BN, Hernandez AM, Taylor CR, Hamilton AS, Deapen DM, Rappaport EB. 1995. Concordance for Hodgkin's disease in identical twins suggesting genetic susceptibility to the young-adult form of the disease. $N$ Engl J Med 332: 413418. doi:10.1056/NEJM199502163320701

Mandal R, Bolt DM, Shah BK. 2013. Disparities in chronic myeloid leukemia survival by age, gender, and ethnicity in pre- and post-imatinib eras in the US. Acta Oncol 52: 837-841. doi:10.3109/0284186X.2012.707784

Manns A, Cleghorn FR, Falk RT, Hanchard B, Jaffe ES, Bartholomew C, Hartge P, Benichou J, Blattner WA. 1993. Role of HTLV-I in development of non-Hodgkin lymphoma in Jamaica and Trinidad and Tobago. The HTLV lymphoma study group. Lancet 342: 1447-1450. doi:10.1016/0140-6736(93)92931-I

Matsuo K, Kusano A, Sugumar A, Nakamura S, Tajima K, Mueller NE. 2004. Effect of hepatitis C virus infection on the risk of non-Hodgkin's lymphoma: A meta-analysis of epidemiological studies. Cancer Sci 95: 745-752. doi:10 $.1111 /$ j.1349-7006.2004.tb03256.x

Metz-Flamant C, Samson E, Caër-Lorho S, Acker A, Laurier D. 2012. Leukemia risk associated with chronic external exposure to ionizing radiation in a French cohort of nuclear workers. Radiat Res 178: 489-498. doi:10.1667/ RR2822.1

Miranda-Filho A, Piñeros M, Ferlay J, Soerjomataram I, Monnereau A, Bray F. 2018. Epidemiological patterns of leukaemia in 184 countries: A population-based study. Lancet Haematol 5: e14-e24. doi:10.1016/S2352-3026 (17)30232-6

Mohan AK, Hauptmann M, Freedman DM, Ron E, Matanoski GM, Lubin JH, Alexander BH, Boice JD Jr, Morin Doody M, Linet MS. 2003. Cancer and other causes of mortality among radiologic technologists in the United States. Int J Cancer 103: 259-267. doi:10.1002/ijc.10811

Monnereau A, Glaser SL, Schupp CW, Ekström Smedby K, de Sanjosé S, Kane E, Melbye M, Forétova L, Maynadié M, Staines A, et al. 2013. Exposure to UV radiation and risk of Hodgkin lymphoma: A pooled analysis. Blood 122: 3492-3499. doi:10.1182/blood-2013-04-497586

Moormann AM, Snider CJ, Chelimo K. 2011. The company malaria keeps: How co-infection with Epstein-Barr virus leads to endemic Burkitt lymphoma. Curr Opin Infect Dis 24: 435-441. doi:10.1097/QCO.0b013e328349ac4f

Morton LM, Hartge P, Holford TR, Holly EA, Chiu BC, Vineis P, Stagnaro E, Willett EV, Franceschi S, La Vecchia C, et al. 2005. Cigarette smoking and risk of non-Hodgkin lymphoma: A pooled analysis from the international lymphoma epidemiology consortium (interlymph). Cancer Epidemiol Biomarkers Prev 14: 925-933. doi:10.1158/ 1055-9965.EPI-04-0693

Morton LM, Dores GM, Tucker MA, Kim CJ, Onel K, Gilbert ES, Fraumeni JF Jr, Curtis RE. 2013. Evolving risk of therapy-related acute myeloid leukemia following cancer chemotherapy among adults in the United States, 19752008. Blood 121: 2996-3004. doi:10.1182/blood-201208-448068
Morton LM, Slager SL, Cerhan JR, Wang SS, Vajdic CM, Skibola CF, Bracci PM, de Sanjose S, Smedby KE, Chiu $\mathrm{BC}$, et al. 2014. Etiologic heterogeneity among nonHodgkin lymphoma subtypes: The InterLymph nonHodgkin lymphoma subtypes project. J Natl Cancer Inst Monographs 2014: 130-144. doi:10.1093/jncimono graphs/lgu013

Mutalima N, Molyneux E, Jaffe H, Kamiza S, Borgstein E, Mkandawire N, Liomba G, Batumba M, Lagos D, Gratrix F, et al. 2008. Associations between Burkitt lymphoma among children in Malawi and infection with HIV, EBV and malaria: Results from a case-control study. PLoS ONE 3: e2505. doi:10.1371/journal.pone.0002505

Noone A, Howlader N, Krapcho M, Miller D, Brest A, Yu M, Ruhl J, Tatalovich Z, Mariotto A, Lewis D, et al. 2017. SEER Cancer Statistics Review, 1975-2015. National Cancer Institute, Bethesda, Maryland.

Oksenhendler E, Boulanger E, Galicier L, Du MQ, Dupin N, Diss TC, Hamoudi R, Daniel MT, Agbalika F, Boshoff C, et al. 2002. High incidence of Kaposi sarcoma-associated herpesvirus-related non-Hodgkin's lymphoma in patients with HIV infection and multicentric Castleman disease. Blood 99: 2331-2336. doi:10.1182/blood.V99.7 .2331

Orem J, Mbidde EK, Lambert B, de Sanjose S, Weiderpass E. 2007. Burkitt's lymphoma in Africa, a review of the epidemiology and etiology. Afr Health Sci 7: 166-175.

Owen C, Barnett M, Fitzgibbon J. 2008. Familial myelodysplasia and acute myeloid leukaemia-A review. $\mathrm{Br} \mathrm{J}$ Haematol 140: 123-132. doi:10.1111/j.1365-2141.2007 .06909.x

Pan JW, Cook LS, Schwartz SM, Weis NS. 2002. Incidence of leukemia in Asian migrants to the United States and their descendants. Cancer Causes Control 13: 791-795. doi:10 .1023/A:1020608328969

Parsonnet J, Hansen S, Rodriguez L, Gelb AB, Warnke RA, Jellum E, Orentreich N, Vogelman JH, Friedman GD. 1994. Helicobacter pylori infection and gastric lymphoma. N Engl J Med 330: 1267-1271. doi:10.1056/ NEJM199405053301803

Patel MI, Ma Y, Mitchell BS, Rhoads KF. 2012. Understanding disparities in leukemia: A national study. Cancer Causes Control 23: 1831-1837. doi:10.1007/s10552-0120062-3

Patel MI, Ma Y, Mitchell B, Rhoads KF. 2015a. How do differences in treatment impact racial and ethnic disparities in acute myeloid leukemia? Cancer Epidemiol Biomarkers Prev 24: 344-349. doi:10.1158/1055-9965.EPI14-0963

Patel MI, Ma Y, Mitchell BS, Rhoads KF. 2015b. Age and genetics: How do prognostic factors at diagnosis explain disparities in acute myeloid leukemia? Am J Clin Oncol 38: 159-164. doi:10.1097/COC.0b013e31828d7536

Pearce MS, Salotti JA, Little MP, McHugh K, Lee C, Kim KP, Howe NL, Ronckers CM, Rajaraman P, Sir Craft AW, et al. 2012. Radiation exposure from CT scans in childhood and subsequent risk of leukaemia and brain tumours: A retrospective cohort study. Lancet 380: 499-505. doi:10 .1016/S0140-6736(12)60815-0

Preston DL, Kusumi S, Tomonaga M, Izumi S, Ron E, Kuramoto A, Kamada N, Dohy H, Matsuo T, Matsui T, et al 1994. Cancer incidence in atomic bomb survivors. Part 
III: Leukemia, lymphoma and multiple myeloma, 19501987. Radiat Res 137: S68-S97. doi:10.2307/3578893

Pui CH, Relling MV, Downing JR. 2004. Acute lymphoblastic leukemia. N Engl J Med 350: 1535-1548. doi:10.1056/ NEJMra023001

Pui C-H, Pei D, Pappo AS, Howard SC, Cheng C, Sandlund JT, Furman WL, Ribeiro RC, Spunt SL, Rubnitz JE, et al. 2012. Treatment outcomes in black and white children with cancer: Results from the SEER database and St Jude Children's Research Hospital, 1992 through 2007. J Clin Oncol 30: 2005-2012. doi:10.1200/JCO.2011.40.8617

Pulte D, Redaniel MT, Jansen L, Brenner H, Jeffreys M. 2013. Recent trends in survival of adult patients with acute leukemia: Overall improvements, but persistent and partly increasing disparity in survival of patients from minority groups. Haematologica 98: 222-229. doi:10.3324/haema tol.2012.063602

Raaschou-Nielsen O, Hvidtfeldt UA, Roswall N, Hertel O, Poulsen AH, Sørensen M. 2018. Ambient benzene at the residence and risk for subtypes of childhood leukemia, lymphoma and CNS tumor. Int J Cancer 143: 13671373. doi:10.1002/ijc.31421

Rawstron AC, Yuille MR, Fuller J, Cullen M, Kennedy B, Richards SJ, Jack AS, Matutes E, Catovsky D, Hillmen $\mathrm{P}$, et al. 2002. Inherited predisposition to CLL is detectable as subclinical monoclonal B-lymphocyte expansion. Blood 100: 2289-2290. doi:10.1182/blood-2002-03-0892

Řeřicha V, Kulich M, Reřicha R, Shore DL, Sandler DP. 2006. Incidence of leukemia, lymphoma, and multiple myeloma in Czech uranium miners: A case and cohort study. Environ Health Perspect 114: 818-822. doi:10.1289/ehp .8476

Richardson DB, Wing S, Schroeder J, Schmitz-Feuerhake I, Hoffmann W. 2005. Ionizing radiation and chronic lymphocytic leukemia. Environ Health Perspect 113: 1-5. doi:10.1289/ehp.7433

Richardson D, Sugiyama H, Nishi N, Sakata R, Shimizu Y, Grant EJ, Soda M, Hsu WL, Suyama A, Kodama K, et al 2009. Ionizing radiation and leukemia mortality among Japanese atomic bomb survivors, 1950-2000. Radiat Res 172: 368-382. doi:10.1667/RR1801.1

Rochford R, Cannon MJ, Moormann AM. 2005. Endemic Burkitt's lymphoma: A polymicrobial disease? Nat Rev Microbiol 3: 182-187. doi:10.1038/nrmicro1089

Rudant J, Orsi L, Monnereau A, Patte C, Pacquement H, Landman-Parker J, Bergeron C, Robert A, Michel G, Lambilliotte A, et al. 2011. Childhood Hodgkin lymphoma, non-Hodgkin lymphoma and factors related to the immune system: The Escale Study (SFCE). Int J Cancer 129: 2236-2247. doi:10.1002/ijc.25862

Rudant J, Lightfoot T, Urayama KY, Petridou E, Dockerty JD, Magnani C, Milne E, Spector LG, Ashton LJ, Dessypris N, et al. 2015. Childhood acute lymphoblastic leukemia and indicators of early immune stimulation: A Childhood Leukemia International Consortium study. Am J Epidemiol 181: 549-562. doi:10.1093/aje/kwu298

Sagaert X, Van Cutsem E, De Hertogh G, Geboes K, Tousseyn T. 2010. Gastric MALT lymphoma: A model of chronic inflammation-induced tumor development. Nat Rev Gastroenterol Hepatol 7: 336-346. doi:10.1038/nrgas tro.2010.58
Sakata R, Kleinerman RA, Mabuchi K, Stovall M, Smith SA, Weathers R, Wactawski-Wende J, Cookfair DL, Boice JD Jr, Inskip PD. 2012. Cancer mortality following radiotherapy for benign gynecologic disorders. Radiat Res 178: 266-279. doi:10.1667/RR2845.1

Saso R, Kulkarni S, Mitchell P, Treleaven J, Swansbury GJ, Mehta J, Powles R, Ashley S, Kuan A, Powles T. 2000. Secondary myelodysplastic syndrome/acute myeloid leukaemia following mitoxantrone-based therapy for breast carcinoma. Br J Cancer 83: 91-94. doi:10.1054/bjoc.2000 .1196

Schmiegelow K, Vestergaard T, Nielsen SM, Hjalgrim H. 2008. Etiology of common childhood acute lymphoblastic leukemia: the adrenal hypothesis. Leukemia 22: 21372141. doi:10.1038/leu.2008.212

Shenoy PJ, Malik N, Sinha R, Nooka A, Nastoupil LJ, Smith M, Flowers CR. 2011. Racial differences in the presentation and outcomes of chronic lymphocytic leukemia and variants in the United States. Clin Lymphoma Myeloma Leuk 11: 498-506. doi:10.1016/j.clml.2011.07.002

Shiels MS, Engels EA, Linet MS, Clarke CA, Li J, Hall HI, Hartge P, Morton LM. 2013. The epidemic of nonHodgkin lymphoma in the United States: Disentangling the effect of HIV, 1992-2009. Cancer Epidemiol Biomarkers Prev 22: 1069-1078. doi:10.1158/1055-9965.EPI-130040

Siegel DA, Henley SJ, Li J, Pollack LA, Van Dyne EA, White A. 2017. Rates and trends of pediatric acute lymphoblastic leukemia-United States, 2001-2014. MMWR Morb Mortal Wkly Rep 66: 950-954. doi:10.15585/mmwr .mm6636a3

Siegel RL, Miller KD, Jemal A. 2018. Cancer statistics, 2018. CA Cancer J Clin 68: 7-30. doi:10.3322/caac.21442

Silver SR, Hiratzka SL, Schubauer-Berigan MK, Daniels RD. 2007. Chronic lymphocytic leukemia radiogenicity: A systematic review. Cancer Causes Control 18: 1077-1093. doi:10.1007/s10552-007-9048-y

Slager SL, Benavente Y, Blair A, Vermeulen R, Cerhan JR, Costantini AS, Monnereau A, Nieters A, Clavel J, Call TG, et al. 2014. Medical history, lifestyle, family history, and occupational risk factors for chronic lymphocytic leukemia/small lymphocytic lymphoma: The InterLymph non-Hodgkin lymphoma subtypes project. J Natl Cancer Inst Monographs 2014: 41-51. doi:10.1093/jncimono graphs/lgu001

Smedby KE, Baecklund E, Askling J. 2006. Malignant lymphomas in autoimmunity and inflammation: A review of risks, risk factors, and lymphoma characteristics. Cancer Epidemiol Biomarkers Prev 15: 2069-2077. doi:10.1158/ 1055-9965.EPI-06-0300

Tai EW, Ward KC, Bonaventure A, Siegel DA, Coleman MP. 2017. Survival among children diagnosed with acute lymphoblastic leukemia in the United States, by race and age, 2001 to 2009: Findings from the CONCORD-2 study. Cancer 123: 5178-5189. doi:10.1002/cncr.30899

Teras LR, DeSantis CE, Cerhan JR, Morton LM, Jemal A, Flowers CR. 2016. 2016 US lymphoid malignancy statistics by World Health Organization subtypes. CA Cancer J Clin 66: 443-459. doi:10.3322/caac.21357

Thomas X, Heiblig M. 2016. Diagnostic and treatment of adult Philadelphia chromosome-positive acute lympho- 
J.A. Baeker Bispo et al.

blastic leukemia. Int J Hematol Oncol 5: 77-90. doi:10 .2217/ijh-2016-0009

Ugai T, Matsuo K, Oze I, Ito H, Wakai K, Wada K, Nagata C, Nakayama T, Liu R, Kitamura Y, et al. 2018. Smoking and subsequent risk of acute myeloid leukaemia: A pooled analysis of 9 cohort studies in Japan. Hematol Oncol 36: 262-268. doi:10.1002/hon.2457

Wang L, Bhatia S, Gomez SL, Yasui Y. 2015. Differential inequality trends over time in survival among U.S. children with acute lymphoblastic leukemia by race/ethnicity, age at diagnosis, and sex. Cancer Epidemiol Biomarkers Prev 24: 1781-1788. doi:10.1158/1055-9965.EPI-15-0639

Ward E, DeSantis C, Robbins A, Kohler B, Jemal A. 2014. Childhood and adolescent cancer statistics, 2014. CA Cancer J Clin 64: 83-103. doi:10.3322/caac.21219

Weisenburger DD. 1994. Epidemiology of non-Hodgkin's lymphoma: Recent findings regarding an emerging epidemic. Ann Oncol 5(Suppl. 1): S19-S24. doi:10.1093/an nonc/5.suppl_1.S19

Wiggins CL, Harlan LC, Nelson HE, Stevens JL, Willman CL, Libby EN, Hromas RA. 2010. Age disparity in the dissemination of imatinib for treating chronic myeloid leukemia. Am J Med 123: 764.e1-764.e9. doi:10.1016/j .amjmed.2010.03.018

Wright JD, St. Clair CM, Deutsch I, Burke WM, Gorrochurn P, Sun X, Herzog TJ. 2010. Pelvic radiotherapy and the risk of secondary leukemia and multiple myeloma. Cancer 116: 2486-2492. doi:10.1002/cncr.25217

Yanik EL, Smith JM, Shiels MS, Clarke CA, Lynch CF, Kahn AR, Koch L, Pawlish KS, Engels EA. 2017. Cancer risk after pediatric solid organ transplantation. Pediatrics 139: e20163893. doi:10.1542/peds.2016-3893

Yoshinaga S, Mabuchi K, Sigurdson AJ, Doody MM, Ron E. 2004. Cancer risks among radiologists and radiologic technologists: Review of epidemiologic studies. Radiology 233: 313-321. doi:10.1148/radiol.2332031119

Zhang Y, Sanjose SD, Bracci PM, Morton LM, Wang R, Brennan P, Hartge P, Boffetta P, Becker N, Maynadie M, et al. 2008. Personal use of hair dye and the risk of certain subtypes of non-Hodgkin lymphoma. Am J Epidemiol 167: 1321-1331. doi:10.1093/aje/kwn058

Zhang L, Steinmaus C, Eastmond DA, Xin XK, Smith MT. 2009. Formaldehyde exposure and leukemia: A new meta-analysis and potential mechanisms. Mutat Res 681: 150-168. doi:10.1016/j.mrrev.2008.07.002

Zhao Y, Wang Y, Ma S. 2018. Racial differences in four leukemia subtypes: Comprehensive descriptive epidemiology. Sci Rep 8: 548. doi:10.1038/s41598-017-19081-4

Zintzaras E, Voulgarelis M, Moutsopoulos HM. 2005. The risk of lymphoma development in autoimmune diseases: A meta-analysis. Arch Intern Med 165: 2337-2344. doi:10 .1001 /archinte.165.20.2337 


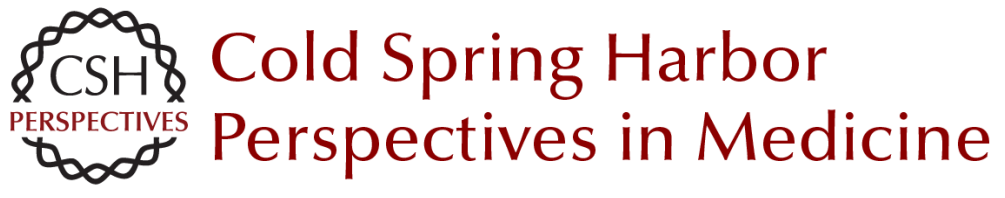

\section{Epidemiology and Etiology of Leukemia and Lymphoma}

Jordan A. Baeker Bispo, Paulo S. Pinheiro and Erin K. Kobetz

Cold Spring Harb Perspect Med 2020; doi: 10.1101/cshperspect.a034819 originally published online November 14, 2019

\section{Subject Collection Leukemia and Lymphoma: Molecular and Therapeutic Insights}

Oncogenic Mechanisms and Therapeutic Targeting of Metabolism in Leukemia and Lymphoma

Maximilian Stahl, Zachary D. Epstein-Peterson and Andrew M. Intlekofer

Non-Hodgkin Lymphomas: Malignancies Arising from Mature B Cells Jennifer Shingleton, Jie Wang, Carolyn Baloh, et al.

MAP-Kinase-Driven Hematopoietic Neoplasms: A Decade of Progress in the Molecular Age Rikhia Chakraborty, Omar Abdel-Wahab and Benjamin H. Durham

Mouse Models in the Study of Mature B-Cell Malignancies Laura Pasqualucci and Ulf Klein

Mouse Models of Myeloid Malignancies Faisal Basheer and George Vassiliou

Epigenetic Mechanisms in Leukemias and Lymphomas

Cihangir Duy, Wendy Béguelin and Ari Melnick

The Biology of B-Progenitor Acute Lymphoblastic Leukemia

Kathryn G. Roberts and Charles G. Mullighan

RNA Regulators in Leukemia and Lymphoma Camila Prieto and Michael G. Kharas
Biological and Translational Considerations regarding the Recent Therapeutic Successes and Upcoming Challenges for Multiple Myeloma Constantine S. Mitsiades

Biology and Molecular Pathogenesis of Mature T-Cell Lymphomas José R. Cortés and Teresa Palomero

The Role of Somatic Mutations in Acute Myeloid Leukemia Pathogenesis Ashwin Kishtagari and Ross L. Levine

Chronic Lymphocytic Leukemia Nicholas Chiorazzi, Shih-Shih Chen and Kanti R. Rai

Normal Hematopoiesis Is a Balancing Act of

Self-Renewal and Regeneration Oakley C. Olson, Yoon-A Kang and Emmanuelle Passegué

Impact of Genetics on Mature Lymphoid

Leukemias and Lymphomas

Nathanael G. Bailey and Kojo S.J. Elenitoba-Johnson

Epidemiology and Etiology of Leukemia and

Lymphoma Jordan A. Baeker Bispo, Paulo S. Pinheiro and Erin K. Kobetz

Clonal Hematopoiesis and Premalignant Diseases Justin Kaner, Pinkal Desai, Nuria Mencia-Trinchant, et al.

For additional articles in this collection, see http://perspectivesinmedicine.cshlp.org/cgi/collection/ 